\title{
Evaluation and design of innovation policies in the agro-food sector: An application of multilevel self-regulating agents
}

\author{
Dimitri Gagliardi ${ }^{\mathrm{a}, *}$, Francesco Niglia $^{\mathrm{b}}$, Cinzia Battistella $^{\mathrm{c}}$ \\ a Manchester Institute of Innovation Research, MBS, the University of Manchester, Manchester, UK \\ b KoySLab ltd. Lecce, via Leuca, 174, 73100 Lecce, Italy \\ ${ }^{\text {c }}$ Faculty of Science and Technology, Free University of Bozen-Bolzano, piazza Università 5, 39100 Bozen-Bolzano, Italy
}

\section{A R T I C L E I N F O}

\section{Article history:}

Received 24 September 2012

Received in revised form 15 August 2013

Accepted 11 October 2013

Available online $\mathrm{xxxx}$

\section{Keywords:}

Complex systems dynamics

Agent-based modelling

Innovation policy

Agro-food sector

BDI

JADEX

\begin{abstract}
A B S T R A C T
The aim of this paper is to explore the possibilities offered by agent-base modelling techniques in evaluating the impact of alternative sets of innovation policies on the system where these are implemented and on its actors. The policies selected for this exercise are inspired by the Regional Government's policy document - the Programme for Rural Development (20072013) of the Puglia Region, Italy. These regard, inter alia, the promotion of organic agriculture and GMO-free cultivar, the introduction of a zero-food-miles strategy and new regulations and controls to prevent food adulterations. The paper presents and discusses the results of the simulations showing a trade-off between alternative growth paths and the overall structure of the sector. A "light-touch approach" affects positively smallholdings, associations of microsmall enterprises and the local retail sector by promoting shorter and more rewarding routes to markets for food products. Pursuing the policies more aggressively, will shift the focus of economic activities towards larger enterprises in the primary sector, manufacturing and business services and towards the large distribution for retail, while smallholdings and associations of micro-small enterprises will be increasingly marginalised.
\end{abstract}

Crown Copyright @ 2013 Published by Elsevier Inc. All rights reserved.

\section{Introduction}

The evaluation of the impact of innovation policies on economic systems has been at the centre of the research policy debates for several decades. Evaluation of policy measures and programmes is often seen as a collateral activity of the policy making process. It is usually carried out by or on behalf of funders, sponsors and policy makers to appraise the impact of policy actions either during the implementation stage in order to keep track of the advances, to assess the results obtained. More often these activities are carried out to build new knowledge in evaluation conceptualisation, practices and methods [1-3]. Increasingly, evaluation effort is also deployed in the phases of designing policy measures and programmes (a priori or ex-ante evaluation) in order to learn on the probable/ possible effects of policies and programmes, to gain hindsight

\footnotetext{
* Corresponding author. Tel.: + 44 1612750766; fax: + 441612750923.

E-mail address: dimitri.gagliardi@manchester.ac.uk (D. Gagliardi).
}

and provide valuable input into the policy design at the decision making stage $[4,5]{ }^{1}$

In a recent paper Farmer and Foley [6], after highlighting how modern policy evaluation is still strongly anchored on classical econometric models, the more advanced of which can be traced to the family of dynamics stochastic general equilibrium models - and the serious drawbacks when employed for longer terms policy evaluation - strongly advocate in favour of Agent Based models (ABM). The main reason the authors put forward can be traced to the properties of this family of models and how these pool, within a policy assessment framework, a number of "virtual" decision makers interacting according to certain rules. These simulation models can be as complex as the computational power allows and can

\footnotetext{
${ }^{1}$ Ex-ante evaluation refers to the analysis of strategies: the evaluation of needs, relevance and of the expected impacts. This type of evaluation aims at anticipating policy results, and therefore estimates the economic and social grounds of priorities and objectives.
} 
include diverse categories of agents from consumers to policy makers including institutions such as banks or government agencies. Moreover, these models do not rely on the assumption that the economy will necessarily move towards some sort of predetermined or defined equilibrium given that the dynamics therein described are originated directly from the agents and their interaction (bottom-up) and these interactions might as well be idiosyncratic. Therefore, agent-based modelling can be used in identifying ex-ante the unexpected effects of innovation policy measures and capture differences between the status quo and the results of the proposed actions (different scenarios).

ABMs are nowadays increasingly used for studying diffusion of innovation [7], land use [8], environmental studies [9], supply chain analyses [10], to simulate the financial market [11], the economy [12,13] or regional development [14] amongst others. $\mathrm{AB}$ modelling in agricultural economics and policy has also attracted some interest: Berger [15], Deffuant et al. [16] and Happe et al. [17]. Our paper brings forwards the research plan drafted in Niglia et. al. [18] and aims at exploring further the possibilities offered by the agent-base modelling in explaining the mechanisms underlying the out-reaching effects of policy measures. This aim is accomplished by modelling and simulating the organisations' and systems' reactions through the implementation of alternative strategies without compromising on the statistical properties of econometric modelling techniques or the realism of qualitative evaluation yet probing further into the non-linearities typical of complex economic systems.

In order to validate and showcase the application of our agent-based model as a policy impact assessment tool, the research concentrated on the agro-food sector in Puglia, a region in the south of Italy. This case has been selected as representative of an economic domain in which innovation policy can be determinant in driving regional development.

The first section of the paper presents the theoretical background on agent based modelling, it describes the properties of such models and advances on the philosophy adopted in building the agents and their modus operandi as well as the system of relations. In the second section the authors describe step by step how the agent based model is built around the Puglia Region's agro-food sector, the system of relation between the Region's agents in the agro-food sector, the characteristics of the agents employed in the model as well as the statistical parameterisation of the model. The indicators of the system's performance are also described in this section. The next section presents some important results of the model, showing the effect of a selected type of policies on the structure of the sector by means of a set of indicators chosen to describe agents, category of agents and system's performance. The paper concludes with a discussion of the results, the limitation of the study and a way forward for further research.

\section{Theoretical background and agents' behaviour}

Agent-based modelling is the generic designation of a family of computational techniques used in the simulation of the behaviour of a number of agents acting as decisionmakers in a given environment interacting through prescribed rules [6]. The agents are the key elements of the theory and can be as diverse as needed - from consumers to policy-makers. Their behaviour can be simulated through a set/menu of rules mimicking the behaviour of real world agents to a various degrees of detail. Independently from the models' specifications and the characteristics of the agents, ABMs are particularly suited to describe and analyse the complexities of a system and the interdependencies amongst the agents operating within such system. In fact, in nonmainstream approaches to explain the economic relationships, structural dynamics [18], systemic aspects, complexity and evolution [19-23] emerge that the underlying forces of change are those of selection, diversity and growth. These are driven by the creation, accumulation and application of new knowledge, a complex process that is necessarily bottom-up, and relies on the interconnection of diverse behaviours playing out in a system of relations assuring a certain order [24].

In this context, $\mathrm{AB}$ Models rely firstly on autonomous agents be they consumers, producers or traders - mimicking actual behaviour independently from any overarching rules imposed top-down (i.e. the system and its agents move towards a position of equilibrium). Of course, institutions, policy makers and other regulatory agents can be included in the model and they can negotiate a role of gatekeepers of "order". Also, the environment may introduce constraints to the autonomy of the agents. However, these are features of particular models rather than a priori assumptions on the functioning of the system and the evolution described by such systems is self organising as they emerge spontaneously from the mutual interaction of the agents [25].

Moreover, agents are interdependent: they interact with one another. The behaviour of each agent is bound to affect the behaviours and the actions of others with whom they interact directly or indirectly. As a consequence this raises the possibility that the whole environment can be changed by agents' actions/interactions. In other word agents' actions bear consequences and these affect agents' performance as well as the overall performance of the system in a non linear way.

A third feature of ABMs is that agents follow rules. Such rules might eventually be contextualised to the agents' role within the system; nonetheless the decisions are based on a somewhat predictable set of rules, once again mimicking human behaviour in what can be described as a role play. Usually agents' rules are simple, as simple as those stereotypical rules followed by people in exercising their functions within the system they are embedded. ${ }^{2}$ Agents' simple rules do not, however, limit the possible dynamics of the system under scrutiny.

Finally, and lastly, agents behave accordingly to the information in their possession and adapt to circumstances. Through interaction agents adapt their behaviour though imitating, selecting, replicating behaviours or eventually even learning new options $[27,28]$. It is therefore understood that the basic construct of an ABM centres on the specification of the agents, their roles and characteristics and the rules of interaction with other agents within a system of relations [29].

\footnotetext{
2 To clarify this point is of great help the example drawn by Simon [26], (page 52-53). Simon argues that human behaviour, contextualised within the complexity of a system, can be explained by simple/predictable behaviours. In other words, the reason or the behaviour can be based on an infinitely complex cumulative memory, motivations or emotions, yet the end result or behaviour of an adaptive being will be somehow predictable and reflecting the characteristics of the outer environment (in the light of the goals set)
} 
In the case at hand we based the theoretical foundations of our AB Model on the Belief-Desire-Intention (BDI) architecture introduced by Bratman [30-32] and further formalised by Rao and Georgeff [33]. BDI is understood as a philosophical model for describing rational agents. It consists of the concept of belief, desire and intention as mental attitudes, to mimic human actions. Beliefs capture information or rather constitute the knowledge base of the agent. In this sense the body of knowledge of the agent is somehow coherent in the sense that the agent does not possess contradictory information or conflicting knowledge about what she knows. Furthermore, the agent does not know everything, i.e. their knowledge is incomplete [32]. An agent's desires constitute the motivation for the agent to "play the game". Generally, desires are the goals of the agents; these are expressed as priorities or objectives to be accomplished. A practical definition of desires entails that the objectives or the goals of the agent are somehow achievable ${ }^{3}$ $[33,34]$. Intentions are the deliberative attitudes of agents. They constitute the capacity of the agent to plan ahead and eventually coordinate the activities carried out. Once formed, intentions influence the decision making process in a context of bounded rational behaviour. Bratman et al. ([31], page 349) synthesise the problem of rational behaviour as the production of actions that further the goal of agent, based upon her conception of the world. In particular, while a resource-unbounded agent might be able to determine the optimal course of actions to reach the objective, in a more realistic world, virtual agents (as well as humans) are somehow unable to know of all the variables necessary and constantly perform the necessary calculations to achieving objectives in a changing environment [35]. In this context, intentions, born out of the incomplete knowledge set of the agent (beliefs) and informed by functional (and coherent) desires to accomplish a predetermined status, constitute the available set of possible actions that the agent can perform autonomously (as a decision maker) and interdependently with other agents (as element of a system of relations).

Our model is based on JADEX technology employed to facilitates the use of BDI models in the context of mainstream programming [36]. It does so by replicating the scheme proposed by Bratman [30,31] and operationalised by Rao and Georgeff $[33,34]$ whereby beliefs, goals and plans are first class objects in the programming and can be created and manipulated within the agent's processes.

Beliefs are stored in a "beliefbase" that comprises the "facts" known by the agent. The beliefbase consists in a collection of information that is regularly updated (also during runtime) according to new information collected during the interaction phase. In case of changes of beliefs, a query-like feature is activated and the new beliefs are dynamically evaluated.

The agent considers the desires, in the first instance, as achievable or not achievable, and in the second instance: 1) as an option - the agents decide to add it to the structure of desires, 2 ) as active - to pursue through appropriate actions

\footnotetext{
${ }^{3}$ Rao and Georgeff [33] make the distinction between desires and accessible goals in order to discern between seemingly unfounded desires and those that show consistency with the "world" within which the agents are operating. In other words, accessible goals are those realistic expectations founded on the knowledge base of the agent and that can eventually develop into intentions to act.
}

or 3) suspended - it will be kept and re-evaluated in another context.

The actual actions undertaken by the agent to carry out its goals are part of the intentions. In this framework, a plan/ intention comprises two stages 1) the conditions under which a plan might be executed and 2) the procedures, describing the plan, through which the agent reacts to the event it is presented with. During the execution of a plan, the agent might either a) act upon it according to the procedures indicated, b) wait until a trigger event occurs or c) wait for a set of conditions to be verified.

\section{The representation of the agro-food system in the Region of Puglia: from the economic and policy framework to ABM specification, implementation, and validation}

In the Puglia Region of Italy there are some 245 thousand companies and organisations, mostly SMEs, engaged in the agro-food industry employing some $10 \%$ of the regional workforce (Italian average: $5 \%$ ). The regional agro-food sector constitutes $15 \%$ of the total national agro-food sector ([37] Data 2010). In 2007, the value of production was of $€ 3.4$ b; of these, 39\% came from arboreal cultures, mainly olives and grapes. Potatoes and other vegetables constitute the $37 \%$ of the total value. The remnant $24 \%$ of the sector's value is given by agricultural services (14\%), meat (9\%) and feedstock (1\%).

\subsection{Policy framework}

The regional government of Puglia is engaging in the agriculture policy through the Programme for Rural Development (PRD) [38]. ${ }^{4}$ The current programme laid down for the period 2007-2013 in line with the EC regulations (n. 1698/2005 and $1974 / 2006$ ) is strategically oriented towards reaching the "maximum efficiency of public support for agriculture".

Limiting our analysis to the agro-food sector, ${ }^{5}$ the aim of the PRD is to promote diversification of cultures and eventually shifting the production from arboreal cultures (where international competitors are strengthening market positions) to a more entrepreneurial vision of the local agricultural economy. In pursuing this objective the regional policy is concentrating its effort in promoting development paths consistent with the renovation of the sector and providing services to agricultural companies and entrepreneurs willing to adhere to this vision. In particular the areas of intervention comprise 1) improve productivity of agriculture and forestry; 2) increase and maintain the value of the environment and rural areas through land and territory management and 3 ) increase quality of life in rural areas and support diversification of economic activities. Within the first macro-area, policy measures centre on the whole value chain associated with the agriculture sector; in fact the objective is to innovate and develop the traditional agro-food sector involving the producers as well as businesses operating along the value chain "from fields to tables"

\footnotetext{
4 The Programme for Rural Development (Programma di Sviluppo Rurale 2005-2013) of the Puglia Region is also part of the wider National Programme for Development (PSN).

5 The PRD of the Puglia Region has a remit not only extending to the agriculture but also to forestry, environment and land and territory management amongst other areas.
} 
capitalising on local resources, products of excellence from organic agricultural practices and develop a regional network of entrepreneurial businesses including agriculture businesses, service providers, manufacturers and distributors.

\subsection{The model and the agents' categories of the agro-food system}

The regional agro-food system has been modelled on the actual data available from official databases [37]. This formalisation has been used to evaluate the variables pertaining to each agent and to collate the time series against which we benchmarked our simulations. In doing so we were able to provide the metrics that are then used to define statistically the agents and fine-tuning the simulation.

The authors identified 18 agents in the system; each agent represents a different category of actors in the agro-food sector, including the final consumers. These agents distributed within the systems according to their main economic role in the value-chain. Following Marotta and Perito [39], we have matched the economic operators of the agro-food to their respective role in the value chain. The agent/economic operator scheme deployed for the Puglia Region agro-food sector consists of three main macro layers (Fig. 1), the arrows indicate the route of the products, from the producers to the consumers. ${ }^{6}$

Each agent identifies a category of economic actors and the arrows indicate the connections and the direction of the exchange of goods. When two agents are linked by an arrow in Fig. 1, goods move between them in the direction of the arrow.

The first layer, "producers", comprises three agents: smallholdings, small producers and their associations (including cooperatives of producers), and medium and large agricultural enterprises. The second layer includes nine agents corresponding to the manufacturing and business services and comprises those economic operators engaged in intermediate activities from produce picking to the transformation, storage and wholesale of the final products. The third layer includes four agents representing the retail sector, including stalls and shops, retailer, small chains and supermarkets.

To complete the value chain we have also added a further class of agents representing the final consumers: auto consumers, absorbing a small but significant share of the produce, and the "consumers", exerting their demand on the retail sector.

The relations amongst the agro-food categories (agents) consist in a stylised set of action. These are: 1) exchange of

\footnotetext{
${ }^{6}$ For simplicity, Fig. 1 represents only the exchange of goods $[\mathrm{M}]$, describing the links between each seller and each buyer. Other factors that influence the agents in the model and their behaviour within the socioeconomic context of the agro-food sector are, in order of relevance: 1) the performance/sustainability of the agent itself; 2) the performance/sustainability of each category of buyer and seller that have a direct relationship with the agent; and 3) the performance/sustainability of the whole system. The algorithm discussed in Fig. 2 (below) is able to weight each of the 3 factors by means of recording the status and the variation of the variables Revenues [R], number of companies $[\mathrm{Q}]$, sector employment $[\mathrm{N}]$ - and the relationships amongst them: $[R]$, for example, depends on the negotiations between agents at each steps of simulation, while variations in $[\mathrm{Q}]$ and $[\mathrm{N}]$ are calculated through accountancy relations at the various levels.
}

goods; 2) exchange of money; 3 ) definition of contracts and 4) communication/branding ${ }^{7}$ on the supply chain.

The dynamics of the model is governed by the behaviours of all agents. The typified behaviours are extrapolated from the data analysis. The system dynamics has been analysed and transferred in software routines.

\subsection{The indicators for the system}

We have introduced a set of indicators in order summarise the evolution of the variables and the system's dynamics during each step of the simulation. Four indicators reflect the main factors characterising the agro-food environment, i.e.: goods/produces $(M)$, total revenue $(R)$, number of companies $(\mathrm{Q})$, and employment in the sector $(\mathrm{N})$; and a fifth indicator, sustainability, has been added to ascertain the longer term capability of the system to evolve. ${ }^{8}$ The five indicators are:

- I1 "total revenue" = the sum of the revenues of all the agents in the system.

- I2 "total stock" = the sum of the stock value of all the agents in the system.

- I3 "total number of companies" = the sum of the number of companies belonging to all the agent categories in the system.

- I4 "total number of workers" = the sum of the personnel employed in all the agent categories in the system.

- I5 "sustainability" = the capability of the system to preserve companies and work-places defined as a function of the distributions of I3 and I4.

Each indicator is normalised to the value of 1 against its initial value and it is always positive.

\subsection{Agent's behavioural routines and systemic interactions}

The model has been developed on customised native JADEX integrating the main concepts of beliefs, goals and plans onto programmed routines. ${ }^{9}$ Reasoning in JADEX is a process consisting of two interleaved components. On the one hand, the agent reacts to setting its goals, elaborating internal events and incoming messages by selecting and executing plans (means-end reasoning). On the other hand, the agent continuously deliberates about its current goals and decides on consistent subsets of objectives which will be then pursued. Current beliefs influence the deliberation and means-end reasoning processes of the agent, hence, plans may amend current beliefs while they are executed. Changed beliefs in turn may cause internal events leading to the adoption of new goals and the execution of further plans. The

\footnotetext{
${ }^{7}$ For "branding" we intend a set of agent's characteristics describing its reputation. Reputation includes consistency of behaviour, cumulative ability to carry contracts to completion, repeated successful exchanges, and other reputational variables.

${ }^{8}$ The sustainability index, in its most simple form, is calculated as change in employment times the change in the number of firms in order to obtain a concise indicator of the capacity of the sector.

9 The technological platform upon which the system is running is composed as follows. Hardware: CPU: 16 processors Intel XEON X5842 Quadcore - @ $3.20 \mathrm{GHz}$ (64 processors in parallel); RAM: 64 Gb RAM DDR2; and Software: OS Windows XP Professional, JADEX 2.0, 2011 compiled with NetBeans IDE 7.1.1
} 


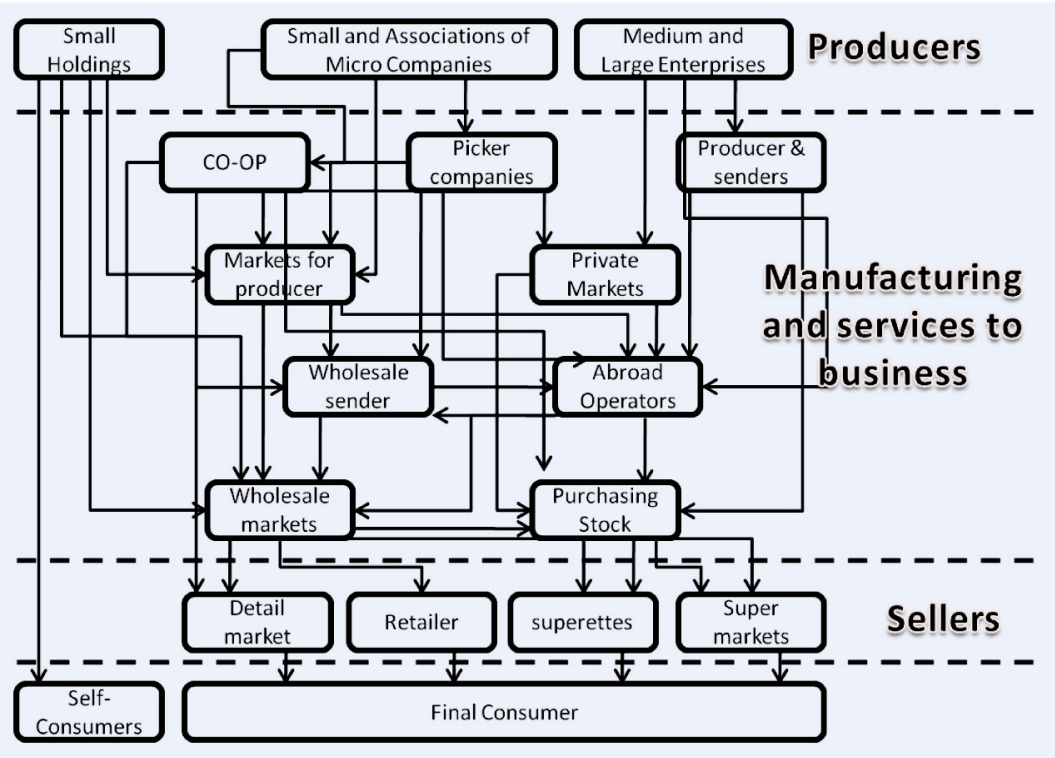

Fig. 1. Interaction amongst agents in the agro-food sector of The Region of Puglia, Italy. Source: adapted from [39].

practical realisation of this process in JADEX is described by the "I/O goods trading" algorithm. JADEX algorithm "I/O goods trading" works as follows: each agent gathers up-to-date information on the status of the system's indicators and includes it in its belief-base variables to generate its new belief-base. All agents use the same behavioural routines traceable to the actions of selling and buying. To these, we included a third routine describing a more complex behaviour deriving from the fact that some agents perform both the roles of buyers and sellers in the supply chain. The actions that our agent may carry out to reach its goals are described by its plans: a procedural algorithm describing the actions to take in order to achieve a goal or react to some event. The characteristics and algorithms of each "type" of agent are described below:

- Buyer. Each buyer agent forwards to its sellers the request to buy goods in the form of quantity of good (M) and relative expected revenue $(R)$ as a command line. It periodically requests all seller agents to provide an offer. As soon as an offer is received the buyer agent decides whether to accept it and issue a purchase order or not. Amongst all the set of offers, the buyer agent accepts the best one evaluated as a combination of the following parameters: price, system performance and sellers' sustainability. Having bought the target quantity of goods, the buyer agent ends its operations.

- Seller. Seller agents continuously wait for requests from buyer agents. When asked to provide an offer for a quantity of goods, they check if the requested goods are in stock; if so, reply with a price offer. Otherwise they terminate the enquiry. When they receive a purchase order they comply and remove the requested goods from their stock. In our model, the sellers are the agents at the top of the scheme.

- Buyer-seller. We introduced a class of agents able to execute two cyclic behaviours: one dedicated to execute requests for offer and the other dedicated to perform purchase orders (Fig. 2 - left). In Fig. 1 the direction of the arrows describes the purchasing order process. In our model, the buyer-sellers are the manufacturing and services to business and the retail sectors in the middle of the scheme.

One of the most important features that JADEX agents provide is the ability to communicate. The communication paradigm adopted is the asynchronous message passing (Fig. 2 - right). Each agent has a mailbox (the agent message queue) where the JADEX runtime posts messages sent by other agents. Whenever a message is posted in said queue the receiving agent is notified.

Each agent takes into account two source of parameters for the evaluation of the actions' preconditions: 1. internal, based on the variables $\mathrm{M}, \mathrm{R}, \mathrm{Q}, \mathrm{N}$ that rule the single agent's characterisation and; 2 . External, that express the status of the overall system including the closer agents that act as buyer and/or seller of the selected agent.

The basic mode of operation is simple: each agent selects a meta-action from its agenda (purchase or sell) and executes it when the action's preconditions hold.

Each simulation step is defined as a shared agreement of all the selling/purchasing actions reached within the whole system. The step is the result of iterated cycles of balancing requests and offers amongst all the agents.

The 18 agents-model is represented by 3 "seller" agents, 13 "buyer-seller" agents and 2 "buyer" agents. Each agent is engaged in selling its products and purchasing products from other agents at satisfying economic conditions basing its decisions on the level of its own stocks. If more than one seller agent provides an offer, the buyer agent accepts the best one (i.e. the lowest price, quality of the produces, characteristics of the suppliers etc.). In order to guarantee a certain stability of the model and introduce a more realistic 

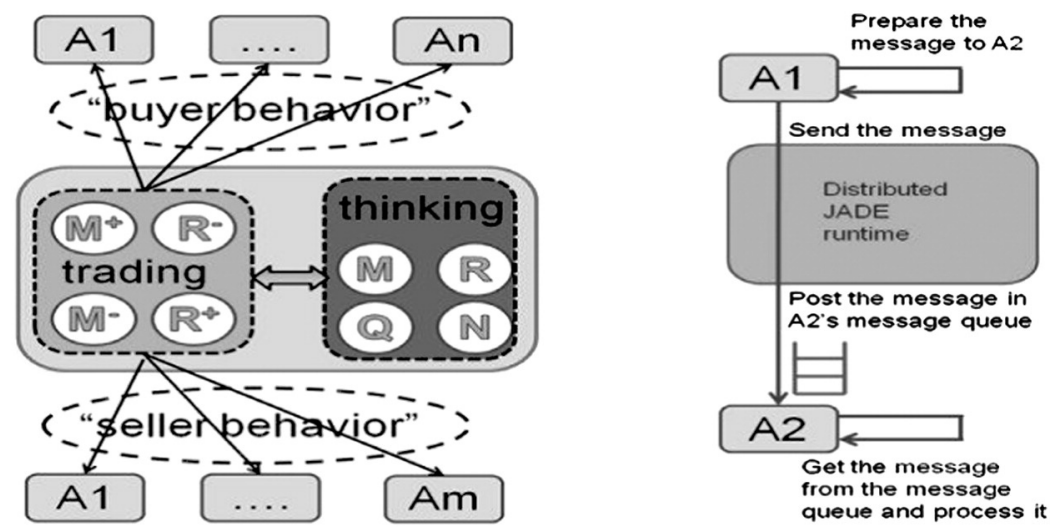

Fig. 2. Scheme of a mixed behaviour for applied agents.

dynamics in the price/quantity relations, we have introduced the working hypothesis that prices and quantities reflect production condition and are somewhat sticky. In other words, the variance of these variables is kept within a certain range. The market dynamics is based on a set of procedures taking into account the evolution of the independent variables $(\mathrm{Q}, \mathrm{N})$ as well as the dynamics of direct variables $(\mathrm{M}, \mathrm{R})$. All operations are based on the concept that the simulation is carried out through steps and it ends when the system has found a stable configuration. ${ }^{10}$ To this end the system's control operates on two levels:

1) Evaluation of each single cycle of the simulation and

2) Evaluation of the system's configuration.

Each simulation cycle terminates when a satisfactory solution in buying-selling is found for all agents within the time necessary for the majority of (neighbour) agents to reach satisfactory contracts, or, if such solution is not reached, the system adopts a hierarchical rule to terminate the step (i.e. a second best configuration is chosen).

\subsection{Tuning up the system of relations}

The procedures followed in tuning up the system of relations and start-up the behaviour of agents are inspired by Fagiolo et al. [40]. Basically, in order to empirically validate the model, we have adopted a two-tier approach. The first tier tackles the problem of linking the ABM system's dynamics to the empirical evidence collected. In doing so, we have set out a statistical representation of the dynamics of the "real world" sector and the historical trends (from 2002 to 2007) on its key variables. The second tier acts upon the relative importance of each agent within the system at time $\mathrm{t}=0$. In other words, given the available data from 1995 to 2010 [37], the ABM is required to perform accordingly to the "historical" dynamics generated by the "real world" in each of the two timeframes. ${ }^{11}$ Through this procedure we have

\footnotetext{
${ }^{10}$ A more detailed description of the algorithm, the levels at which it applies and the concepts that it entails are described in annex.

${ }_{11}$ Please note that the yearly figures presented by the Italian National Statistics Office (ISTAT) and the time-steps used in the model are not correspondent. The fine tuning of the model to the real world data progressed through several attempts to match simulated dynamics with that of the real world (within a confidence interval of 95\%).
}

validated and fine tuned 1) whole system's performance and 2) relative importance - according to the variables under scrutiny - of each agent of the model.

The model works with the discrete percentage variations of the variables calculated as:

$\Delta=\left(\mathrm{X}_{\mathrm{t}}-\mathrm{X}_{\mathrm{t}-1}\right) / \mathrm{X}_{\mathrm{t}-1}$

where $\mathrm{X}$ is the variable at hand.

Hence, the variables can be expressed as:

$\Delta \mathrm{Q}=f($ coeff.$\Delta \mathrm{M}$, coeff.$\Delta \mathrm{R})+$ Error

$\Delta \mathrm{N}=\mathrm{f}($ coeff.$\Delta \mathrm{M}$, coeff $\Delta \mathrm{R}$, coeff $\Delta \mathrm{I})+$ Error.

$\mathrm{M}$ represents the goods/produces, $\mathrm{R}$ the total revenue, $\mathrm{Q}$ the number of companies, $\mathrm{N}$ the employment in the sector, and I represents the gross investment undertaken by the agents.

Once each step of the simulation is considered achieved, the control shifts to the "system" layer. This latter layer provides information about the five system's indicators, updated at the step of reference, and includes a check about the system stability that is evaluated against the stability of indicators themselves as a case of "dynamic stability". Here, dynamic stability is a minimal condition imposed on the system: the system does not behave uncontrollably or the variables become meaningless.

In tuning the model, a buffer or "ghost" agent has been introduced to "smooth" the differences between the modelled (calculated) system and the real economic dynamics that occur in such environments. The buffer agent acts when the system has produced results, it evaluates such results against official data sources and, when there is any divergence, it suggests an adjustment. This process introduces a learning routine in the algorithm that serves the agents in directing their decision making in the subsequent phases by providing them with updated information during the fine-tuning procedures. The approach adopted, at a macro-level, is the following:

Result( simulation $)+$ Result (buffer agent $)=$ Result $($ expected $)$

Result(buffer agent $)=\operatorname{Result}($ official $)-$ Result( simulation $)$. 
At micro-level, the buffer agent is defined through a linear polynomial equation:

$$
\text { Agent }_{\text {BUFFER }}=\sum_{(\mathrm{i}=1, N)} a_{\mathrm{i}} * \mathrm{~V}_{\mathrm{i}}+\sum_{(\mathrm{j}=1, M)} b_{\mathrm{j}} * \mathrm{I}_{\mathrm{j}} .
$$

Where: $N=$ Variables (i as index), $M=$ Indicators ( $\mathrm{j}$ as index), $a, b=$ normalisation coefficients. The linear polynomial equation is recursive, a consistent vector of $a$ and $b$ characterises each solution of $[a, b]$ BUFFER.

\section{Findings}

The findings show the possible outcomes of the system reacting to a naive application of the legal framework aiming at strengthening the production of organic produces and reducing GMO cultivars. ${ }^{12}$ We have built two main scenarios introducing the new policies frameworks aiming at innovating the agricultural and the agro food sector in the region. The policy foundations taken into consideration are those of the Regional Plan for Rural Development namely, the capitalisation on local resources, products of excellence from organic agricultural practices and develop a regional network of entrepreneurial businesses including agriculture businesses, service providers, manufacturers and distributors. These objectives have been summarised in two scenarios. The first encompasses the application of the legal framework to a small percentage of the activities carried out by the businesses. The percentage of application of this legal framework regards at least $5 \%$ of the goods handled. The second setting pushes further the application of the newer legal framework requiring that at least $10 \%$ of the goods handled come from Organic Agricultural practice and GMO-free cultivar and is accordingly certified.

The $5 \%$ and the $10 \%$ scenarios have been taken into consideration for the policy evaluation. A further scenario, where the parameters of the policy intervention have been fixed at $25 \%$, has been introduced as a case limit for the system and has been included for guidance purposes. In fact, it represents a "shock to the system hypothesis" and together with testing the ABM structural stability, gives us some insights into the possible dynamics in extreme conditions [24].

Analysing the results obtained by the simulations on the whole system we can observe that the profile trends for the four variables taken into consideration (revenues, employment, number of companies and stocks) are substantially stable for the $5 \%$ policy scenario showing sustained, yet limited, growth for the first three variables and a more substantial increase in combined stocks handling indicating perhaps a disintermediation in some of the segments of the value chain (Table 1 ). The $10 \%$ policy scenario shows slightly different system dynamics. In the face of a mild growth in revenues (between 1 and $2 \%$ ), the $10 \%$ scenario predicts a drop in the number of companies along the value chain of the agro-food sector $(8 \%)$ and a growth in employment, indicating a net growth in the average size of the enterprises in the sectors.

\footnotetext{
12 The application of the policy framework has been defined "naive" because it has been introduced in the model from a higher level: by the regional government. The dynamics of the system is therefore consequence of the adjustments in production prices defined through subsequent negotiations between agents.
}

Also, a decline in the stocks indicates perhaps a better distribution of the produce along the segments of the value chain.

Sustainability - indicator I5 - is somehow constant for the $5 \%$ policy scenario, indicating that the dynamics of the number of operating companies in the sector and the employment compensates compounded variation. In the $10 \%$ policy scenario, the I5 indicator shows a net gain mainly due to the additional employment generated within the system that more than compensates the reduced number of companies operating (increase of the average size of companies).

The "25\% policy-shock" scenario presents an even different dynamics. It appears that introducing stricter regulation (for a greater percentage of the production) has an effect on the system that would conceivably experience a sharp increase in the concentration of economic activities under the governance of a restricted number of companies which, on average, will be much larger. This strategy promotes a strong vertical integration of the sector with consequences on employment (a sharp rise in employment which is unsustainable in the long term) and would ultimately bring the agro-food sector towards an industrially-run value chain. This is dominated by a strong manufacturing and business services sectors characterised by a small number of very large companies sharing a substantially stable total revenue and logistic/retail sector and also by larger companies that bring to market the lion share of the produce.

The ABM allows a detailed analysis of the various agents. In Figs. 4 and 5 we present the structural dynamics of the three macro-sectors: primary production, manufacturing and business services, and (retail) services (producers, manufacturing and business service providers and sellers) in the case of 5\% and 10\% policy scenario respectively. In particular, the $5 \%$ scenario predicts an overall increase of about $4 \%$ to $5 \%$ in the revenues generated by agro-food sector will be mainly driven by better handling of the stocks: strengthening of the production base (leaner manufacturing and business services) and a stronger retail network (Fig. 3).

Fig. 4 shows how the macro-sectors operating in the system will perform under the $5 \%$ policy scenario. The primary sector (producers) shows a decrease in the number of companies operating but at the same time, the increase in employment within the sector predicts a growth in the average size of the companies. In practical terms, the introduction of the new framework will favour a selection within the sector such that some of the companies will abandon production. The relative increase in the workforce is such that the average size of the remaining companies will be between 3.7 and $5 \%$ larger. To this, the revenue linked to newer productions is increasing (18\%). The effect of the new legal framework on the manufacturing and business services sector is characterised by an increase in the number of companies working on the newer product composition (about 3\%). Such an increase does not correspond to an

\section{Table 1}

Average firms' growth in relative size in terms of employment and in terms of revenue $5 \%$ policy scenario.

\begin{tabular}{lllllllll}
\hline Relative size & \multicolumn{2}{l}{ Producers } & & \multicolumn{2}{l}{ Manufacturers } & & \multicolumn{2}{l}{ Sellers } \\
\cline { 2 - 3 } & Overall & Stable & & Overall & Stable & & Overall & Stable \\
\hline Employment & 0.037 & 0.049 & & -0.026 & 0.002 & & 0.021 & 0.030 \\
Revenue & 0.181 & 0.187 & & -0.090 & -0.134 & & 0.133 & 0.205 \\
\hline
\end{tabular}




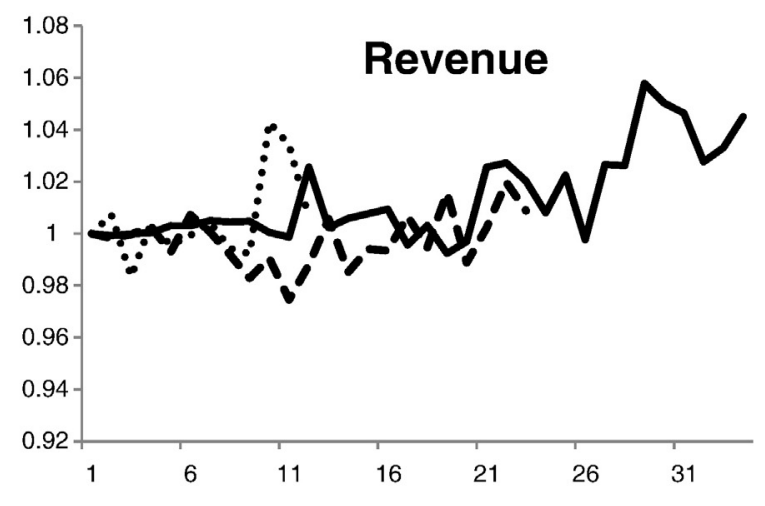

\begin{tabular}{|c|c|c|c|}
\hline Revenue & $\begin{array}{c}\text { Revenue } \\
5 \%\end{array}$ & $\begin{array}{c}\text { Revenue } \\
10 \%\end{array}$ & $\begin{array}{c}\text { Revenue } \\
25 \%\end{array}$ \\
\hline NCycles & 34 & 23 & 12 \\
\hline Mean & 1.0139 & 0.9976 & 1.0052 \\
\hline Median & 1.0054 & 0.9982 & 1.0018 \\
\hline Mean Growth Rate & $1.39 \%$ & $-0.24 \%$ & $0.52 \%$ \\
\hline Std. Error of Mean & 0.0030 & 0.0022 & 0.0049 \\
\hline Std. Deviation & 0.0176 & 0.0106 & 0.0170 \\
\hline
\end{tabular}

a) System's Revenues

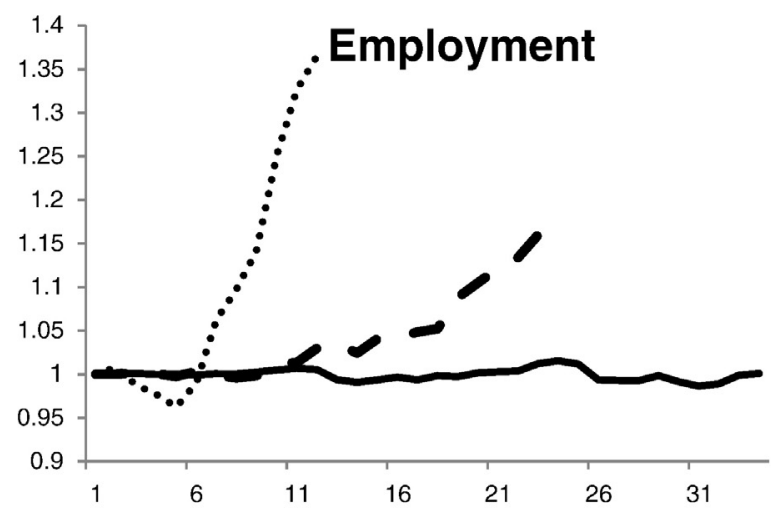

\begin{tabular}{l|lll}
\hline Employment & $\begin{array}{r}\text { Employments } \\
5 \%\end{array}$ & $\begin{array}{l}\text { Employment } \\
10 \%\end{array}$ & \multicolumn{1}{c}{$\begin{array}{c}\text { Employment } \\
25 \%\end{array}$} \\
\hline NCycles & 34 & 23 & 12 \\
Mean & 0.9993 & 1.0392 & 1.0974 \\
Median & 0.9999 & 1.0242 & 1.0354 \\
Mean Growth Rate & $-0.07 \%$ & $3.92 \%$ & $9.74 \%$ \\
Std. Error of Mean & 0.0011 & 0.0102 & 0.0412 \\
Std. Deviation & 0.0065 & 0.0491 & 0.1429 \\
\hline
\end{tabular}

c) Total Employment

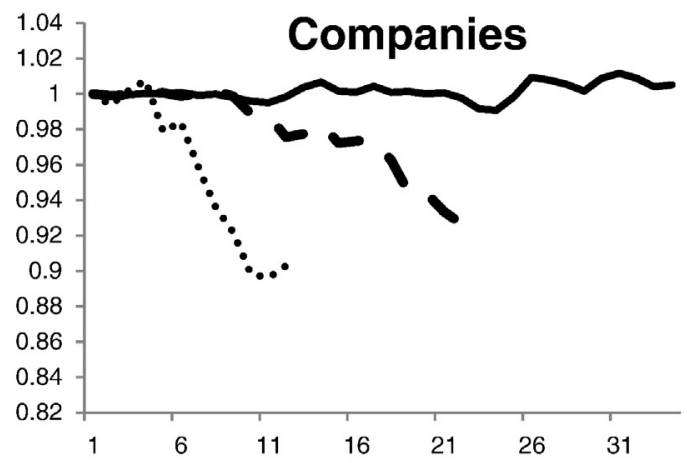

\begin{tabular}{l|lll}
\hline Companies & \multicolumn{1}{|c}{$\begin{array}{c}\text { Companies } \\
5 \%\end{array}$} & $\begin{array}{l}\text { Companies } \\
10 \%\end{array}$ & \multicolumn{1}{c}{$\begin{array}{c}\text { Companies } \\
25 \%\end{array}$} \\
\hline N Cycles & 34 & 23 & 12 \\
Mean & 1.001 & 0.977 & 0.957 \\
Median & 1.001 & 0.983 & 0.969 \\
Mean Growth Rate & $0.14 \%$ & $-2.33 \%$ & $-4.34 \%$ \\
Std. Error of Mean & 0.0008 & 0.0054 & 0.0125 \\
Std. Deviation & 0.0048 & 0.0260 & 0.0434 \\
\hline
\end{tabular}

b) N. of Companies in the System

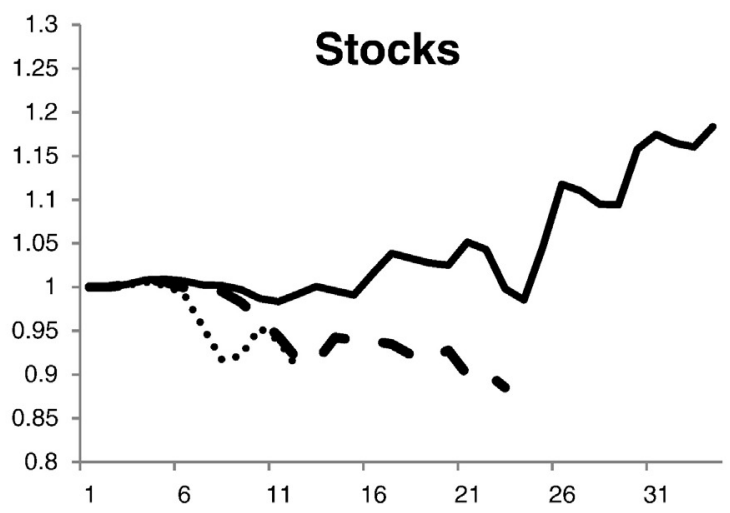

\begin{tabular}{l|lll}
\hline Stocks & \multicolumn{1}{|c}{$\begin{array}{c}\text { Stock } \\
5 \%\end{array}$} & \multicolumn{1}{c}{$\begin{array}{c}\text { Stock } \\
10 \%\end{array}$} & \multicolumn{1}{c}{$\begin{array}{c}\text { Stock } \\
25 \%\end{array}$} \\
\hline N Cycles & 34 & 23 & 12 \\
Mean & 1.0441 & 0.9541 & 0.9662 \\
Median & 1.0124 & 0.9426 & 0.9731 \\
Mean Growth Rate & $4.41 \%$ & $-4.59 \%$ & $-3.38 \%$ \\
Std. Error of Mean & 0.0108 & 0.0085 & 0.0110 \\
Std. Deviation & 0.0631 & 0.0406 & 0.0382 \\
\hline
\end{tabular}

d) Stock of Goods in System

Fig. 3. System's indicators. 


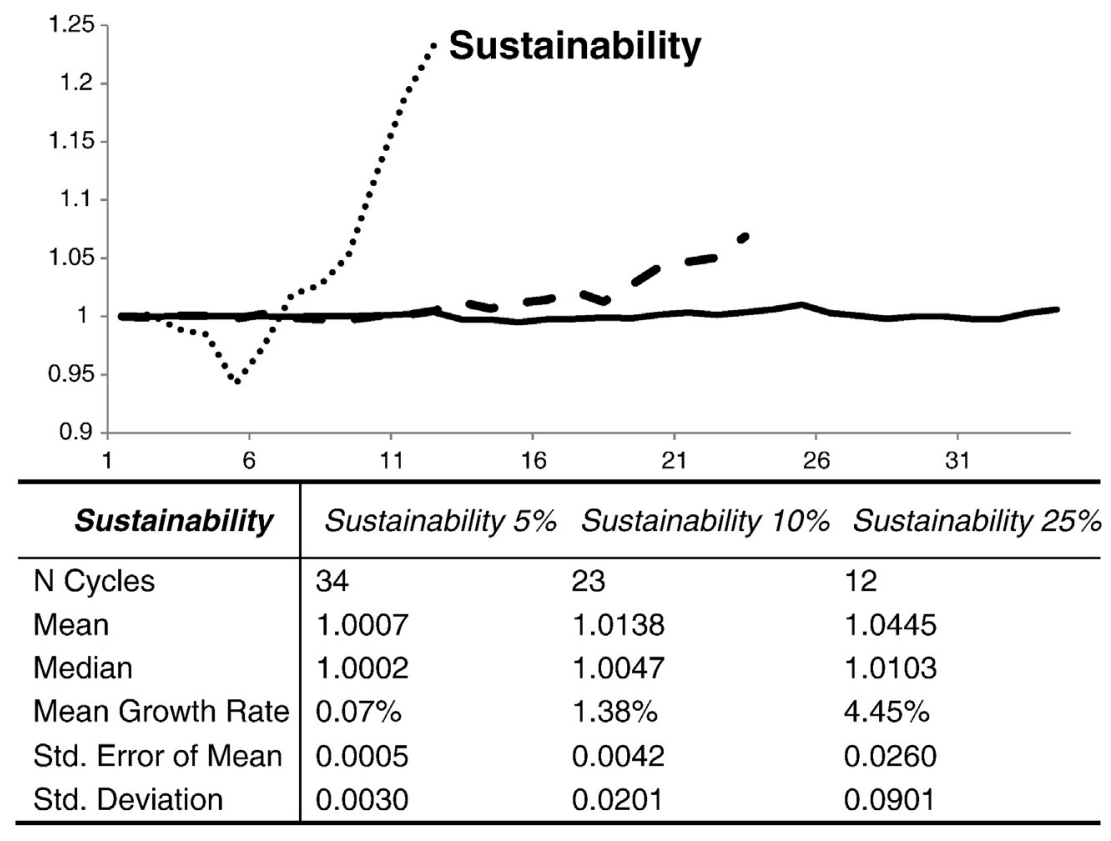

e) Sustainability indicators

- policy $5 \% \quad-$ policy $10 \% \quad \ldots$ policy shock $25 \%$

Fig. 3 (continued).

increase in the size of the sector. In fact the overall size of manufacturing and business services companies is rather stable and the revenues collected are about 13\% lower than before introducing the new legal framework. The retail services sector's performance indicators show that sellers overall decrease in number (on average between 3 and 4\%) however, the increase of employment predicted is such that the size of companies will be on average between 2 and 3\%. At the same time the average size of sellers (measured against revenues) increased by 13 and $20 \%$. This scenario seems to point in the direction of a shortening of the value chain. In fact, the increase in the average size of producers' companies and those of retailers (which increase also the revenues by a substantial percentage (accompanied by stagnation of the manufacturing) is compatible with the hypothesis that fresher produces are generating more business than processed ones.

The second scenario that we have put into action assumes the introduction of the newer legal framework imposing that at least $10 \%$ of the cultivar is organic and GMO-free, the fostering of the zero-miles policy for at least $10 \%$ of the production and controls for adulteration. Fig. 4 shows how the three macro-sectors perform under this new regulation.

In this case, the performance of the primary sector is characterised by a seemingly constant number of companies, however the sizes of the companies are between 3 and 5\% smaller in terms of employment and generate between 7.5 and $12 \%$ less income. On the other hand, the manufacturing and business services and the retail sector show some growth in relative terms. In detail, the number of companies in both sectors decreases on average between 3 and 5\% while the companies grow in terms of both employment and revenue (Table 2).
This scenario - $10 \%$ policy intervention - seems to drive the system towards a more industrialised agro-food sector where the manufacturing and business services and retail services increase their relative weight in the value chain against a decreasing role of producers overall.

Our ABM allows further specifications of the dynamics, in particular regarding the intra-sector structural dynamics. It is in fact possible to analyse how the policy scenarios affect all the agents along the value chain. In particular it is interesting to understand comparably, how the policy scenarios affect the primary sector.

Fig. 6 shows how the two policy scenarios influence the dynamics within the producers' sector. The $5 \%$ policy scenario, predicted an efficiency-driven growth of the primary sector with a negative growth in the number of companies and a relative increase in employment and revenues. Further disaggregation shows that while the small holding segment is substantially stable in terms of all characteristic indicators, the small companies and the associations of micro enterprises experience a reduction in the number of companies but a substantial growth in terms of employment (increasing their relative average size) and a substantial growth in the revenues generated. The ABM predicts that larger companies will marginally strengthen their position with a slight reduction in number (less than $1 \%$ ) and a gain in terms of employment (just over 1\%) which indicate a slight growth in the average size and an average increase in revenues in the region of $1-2 \%$.

Comparatively, the $10 \%$ policy scenario shows a substantial stability of the small holding segment in terms of number of companies, employment and revenues but an eventful dynamics for the small companies and associations of micro enterprises compartment. There is an increase in the number of 
companies (averaging around 5\%) but a substantial decrease in the employment and in revenue generated cause an overall reduction of the segment in the region of about 4-to-5\%. On the other hand the larger segment of the sector experiences minor variation in the number of companies (sensibly less than $1 \%$ ) and a marginal growth in terms of employment and revenues (both just below 1\%).

What does this mean in terms of the sector structural dynamics? In relative terms the two policy scenarios affect the primary macro-sector differently, especially in relation of the role played by small companies and the associations of micro-enterprises. In particular, the $5 \%$ scenario predicts a strengthening of the micro and small enterprises together with a relatively low growth of the larger segment of the sector. This dynamics, contextualised within the overall dynamics of the system, implies that the shortening of the value chain is mainly driven by associations of micro enterprises and small enterprises, while the fabric of the sector is still sustained by the larger companies that increase only marginally their position within the system. The $10 \%$ policy scenario, on the other hand, shifts the value-creation activities towards the manufacturing and the business services. Specifically, the effect on the production sector consists in the shrinking of the small and association of micro enterprises segment and the strengthening of the position of larger companies which bring their produces to markets
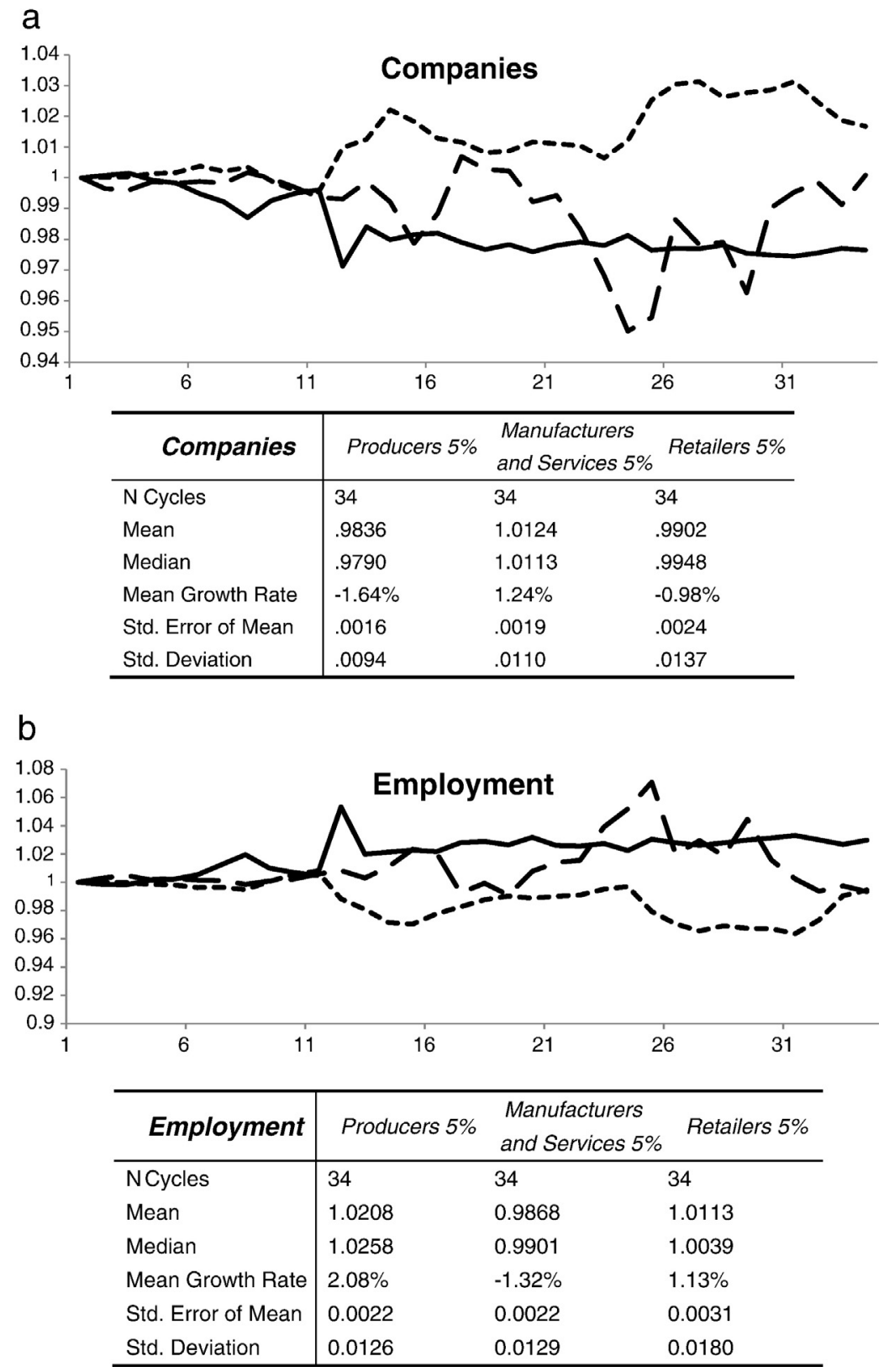

Fig. 4. Companies, employment and revenues in three macro-sectors policy scenario $5 \%$. 


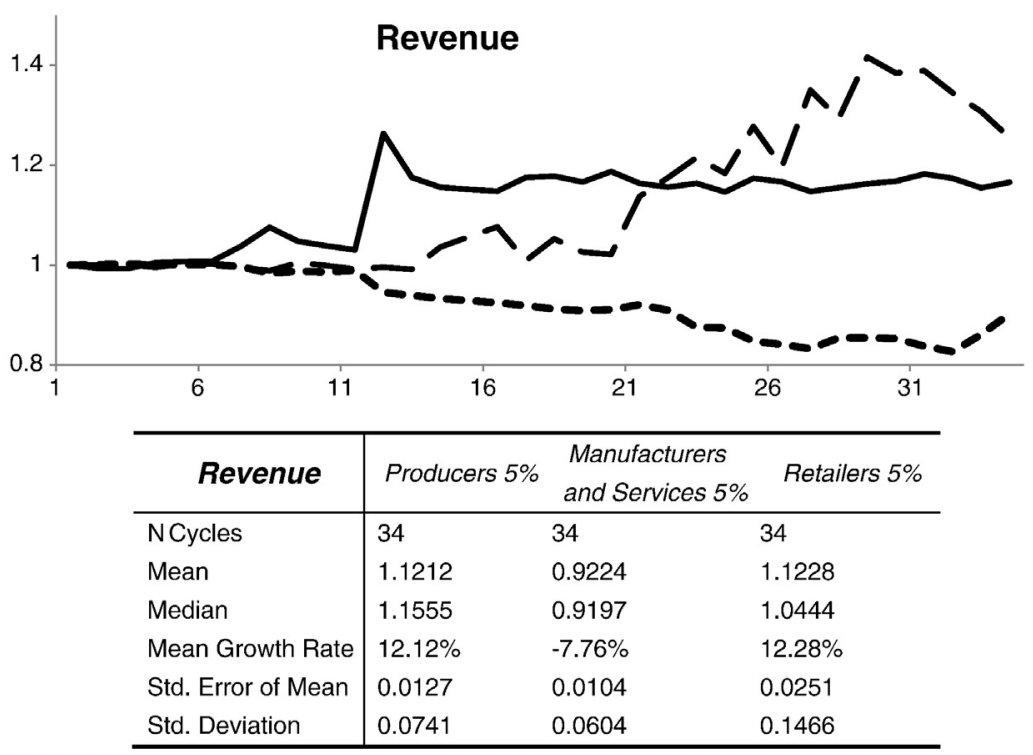

C) Revenues in the three macro-sectors $-5 \%$ policy scenario

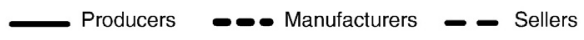

Fig. 4 (continued).

through the network of manufacturers and business services providers.

Finally the $25 \%$ policy shock scenario predicts that the primary sector will be predominantly populated by larger enterprises that will substantially maintain their position throughout the simulation while the small and association of micro-enterprises segment is significantly reduced in terms of number of companies, employment and revenue generated. The value creation has therefore notably shifted towards the operations of transformation and the business services. This sector will result in a concentration of fewer larger companies both in terms of employment and revenue generated. The number of companies in the retail services (sellers) will be greatly reduced while their average size will increase by over $20 \%$ in terms of employment.

\section{Discussions and conclusions}

In brief the three scenarios elaborated through our $\mathrm{AB}$ model, show the impact assessment of the policy measures obtained from the Rural Development Plan of the Region of Puglia. Our elaborations illustrate three possible paths of development of the agro-food system. This exercise puts forward alternative scenarios whereby the system's dynamics - described by the indicators proposed - reacts to the changes "imposed" by the introduction of the legal framework. Given the particular structure of the agro-food sector in the Region, the three settings suggest a long run trade-off between alternative growth paths and the overall structure of the sector.

Our findings show that the implementation of the selected strategies elaborated in the RDP - promotion of organic agriculture and GMO-free cultivar; the introduction of a zero- food-miles strategy and new regulations and controls against food adulterations - will have overall indeterminate consequences on the economy of the sector. In particular, a "light touch approach" (the 5\% policy scenario) will positively influence some segments of the agro-food sector more than others and penalise others. For example the effects of the $5 \%$ policy strategy will be driven by growth in the small and associations of micro-enterprises and the retail sector rather than the more industrial sector comprising manufacturing and business services. The numbers of companies in the primary sector will decline while their relative sizes increase for the small and association of micro-enterprises and the medium and large companies. For this whole segment, the overall revenues will increase substantially. The retail sector, as well, will consist of fewer companies of a relative larger size producing a substantial growth in revenues. The manufacturing and services sector, on the other hand, will still maintain a strong position within the agro-food business with an increase in the number of companies but are smaller in size and their overall revenues will be substantially reduced.

By increasing the pressure on the system, the $10 \%$ policy scenario, the findings show a shift in the drivers of economic growth of the sectors. In fact the agro-food will rely increasingly more on the larger enterprises in the three macro-sectors for its growth. The manufacturing and services sector presents a substantial reduction in the overall number of companies paired with a substantial increase in employment (increasing the relative size of the operating companies) and a substantial increase in the overall revenues produced. At the same time, the retail sector will undergo a concentration whereby less and much larger retailers will share relatively lower revenues. In the primary sector the medium and larger sized companies will 
undergo the process without serious consequences: the number of companies will only marginally decrease while the employment and revenues are marginally rising. The small holdings will instead maintain their status while employment and revenues fall sensibly; the smaller companies - together with the association of micro-enterprises - while growing in number, will be smaller in size and producing sensibly less revenue.
A summary of the findings is summarised in Table 3.

A comparative analysis of the findings presented in Table 3, reveals that a clear superior strategy cannot be singled out unequivocally. The elaborations show that alternatives are indeed available in the phase of designing the policy measures; however, while policy making might benefit from in-depth analyses of this kind, the policy making process and the relative

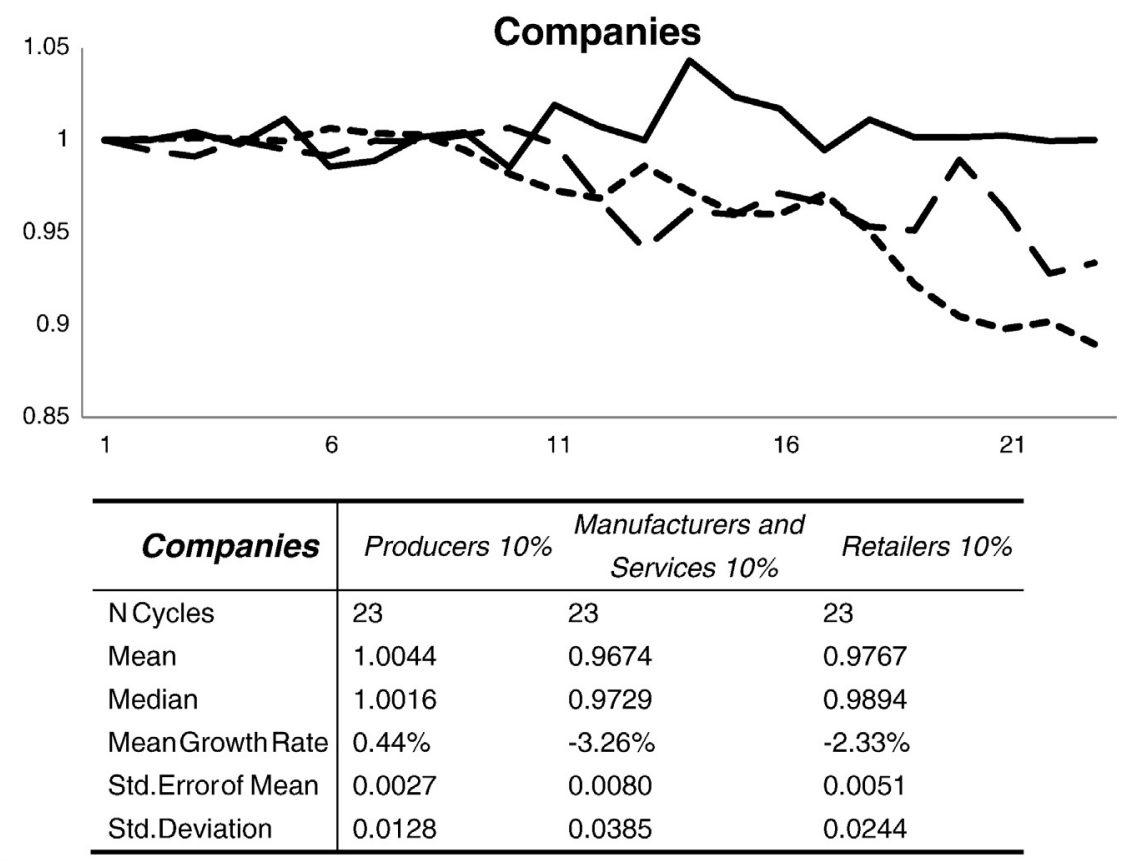

a) N. of companies Producers, Manufacturing and Services - $10 \%$ policy scenario

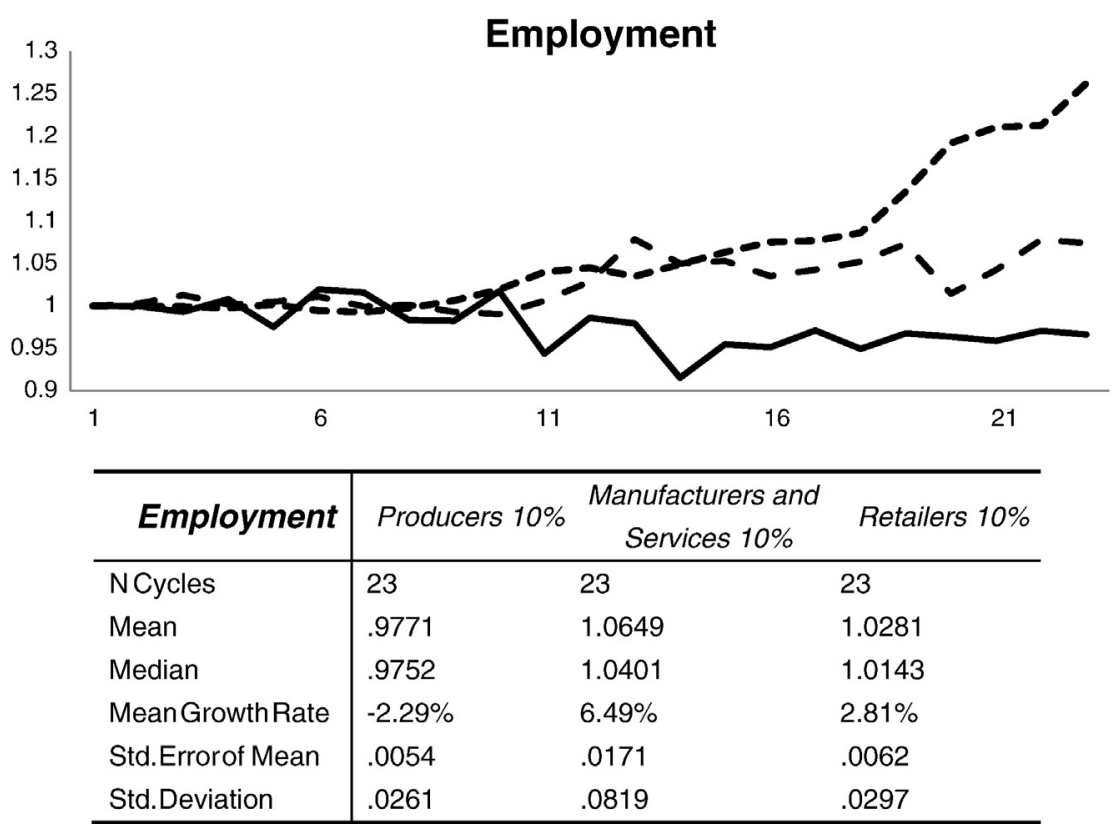

b) Total employment in the three macro-sectors - $10 \%$ policy scenario

Fig. 5. Companies, employment and revenues in three macro-sectors policy scenario $10 \%$. 


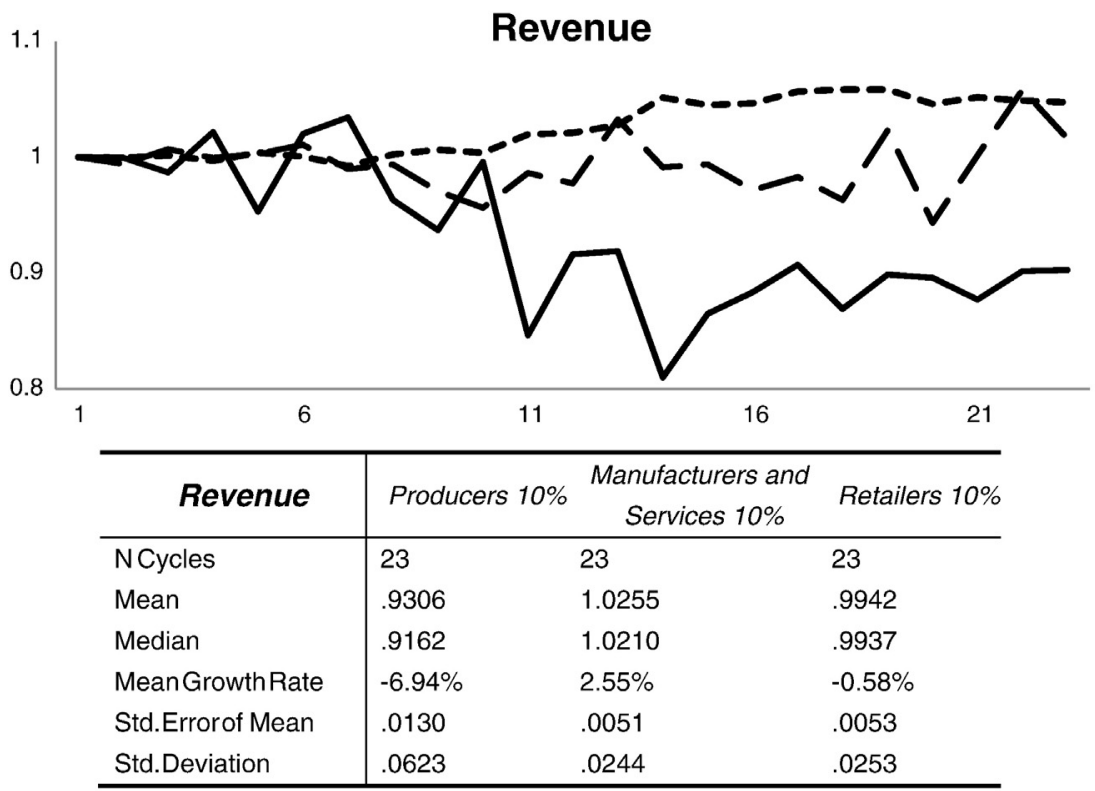

C) Revenues in the three macro-sectors - $10 \%$ policy scenario

—Producers $\quad$-.- Manufacturers $\quad$ - Sellers

Fig. 5 (continued).

implementation will necessarily involve an informed choice between alternatives which might not necessarily be fully comparable.

\subsection{Research agenda: implications and limitations}

This paper has the ambitious objective of adopting Agent Based modelling as a tool for ex-ante policy evaluation. The model used has been built to include elements of a complex economic system: variety of actors, complexity of relations, regulatory framework and organisational dynamics. The agents, characterised by limited knowledge and bounded resources, behave accordingly to their Beliefs, Desires and Intentions whereby the set of rules is adaptive and reactive. Finally, the process is played out on an IT platform where agents' interactions constitute the drivers of the systems.

The results obtained are presented in a way that stepby-step analyses can be carried out and their interpretation can be detailed through a set of indicators summarising the system's and agents' dynamics. We have engaged in the simulation of alternative scenarios where innovation policy options have been evaluated against the policy objective.

The practical implications of our study are manifold but primarily they found their positioning in the domain of ex ante policy evaluation for policy design and learning. In particular, once the model is validated and assessed against historical data, the impact of innovation policies can be assessed at a disaggregated level, for example at the agent's level, or at a more complex level, for example at the level of a group of enterprises, at a production value chain. The policy impact can also be assessed against its systemic objectives.

Alternative hypothesis or policy scenarios can be also evaluated without requiring further modelling.

Furthermore, the baseline model is scalable and may be used to account for single actors (i.e. 1 JADEX agent $=1$ company, organisation or institution) or for larger geopolitical areas. Nonetheless, while this scalability depends mostly on the computational power available and the resources employed to the task, the statistical properties of the model will necessarily "suffer" from the increase in complexity due to the increased variety of actors' behaviour and the exponential increase in the relational networks amongst the agents.

Our effort to build a background methodology capitalising on JADEX properties improves on ex ante evaluations and provides critical inputs into the policy design phase in terms of comparative expected impact. The approach developed pushes the boundaries of policy impact assessment through the application of advanced/complex system simulations using seemingly "intelligent" agents; at the same time conceptual issues like structural uncertainty that are typical of these studies

Table 2

Average firms' growth in relative size in terms of employment and in terms of revenue $10 \%$ policy scenario.

\begin{tabular}{|c|c|c|c|c|c|c|}
\hline \multirow[t]{2}{*}{ Relative size } & \multicolumn{2}{|c|}{ Producers } & \multicolumn{2}{|c|}{ Manufacturers } & \multicolumn{2}{|l|}{ Sellers } \\
\hline & Overall & Stable & Overall & Stable & Overall & Stable \\
\hline Employment & -0.027 & -0.048 & 0.097 & 0.166 & 0.051 & 0.086 \\
\hline Revenue & -0.074 & -0.122 & 0.058 & 0.098 & 0.017 & 0.034 \\
\hline
\end{tabular}


cannot be fully endogeneised in order to take into consideration all possible states of the system.

This disadvantage can be only partially overcome by integrating the model with complementary and alternative hypotheses and evaluate possible impacts that might have on the system under scrutiny and on the behaviour/performance of its agents.

The research agenda developing from this approach develops along two streams of enquiry: 1) evaluate the efficiency of this approach by applying it to comparable cases in other regional settings or in other sectors; 2) extend the features of models to overcome shortcoming linked to the introduction of naive policy options, hence making the policy alternative endogenous to the system as an "ingredient" of the agents' behaviour.

\section{Acknowledgements}

The authors gratefully acknowledge funding from the Region of Puglia-Italy, under POR Puglia 2007-2013, Asse I - linea di Intervento 1.1 - Azione 1.1.2 "Aiuti agli investimenti in Ricerca per le PMI". The results presented in this paper are based on the research and development activities of the project MAESTRO. Dimitri Gagliardi also acknowledges the support from the Autonomous Province of Trento - Grandi Progetti - 2006 (OPENLOC). The authors are also grateful to Dr Ronald Ramlogan who has taken the time to advise us on many issues related to this research. Usual disclaimers apply.

\section{Appendix A}

The variables $\mathrm{M}$ (goods/produces), $\mathrm{R}$ (revenue), $\mathrm{Q}$ (number of companies) and $\mathrm{N}$ (employment) are taken into consideration and for each every agent and at all levels:

- Agent level $\{a\}$ - each agent is associated with all other agents with whom it comes into contact and the variables describe the nature of their interaction.

- Category level indicators are grouped as follows: buyers $\{b\}$ and sellers $\{s\}$ of the goods to and from the agent, each

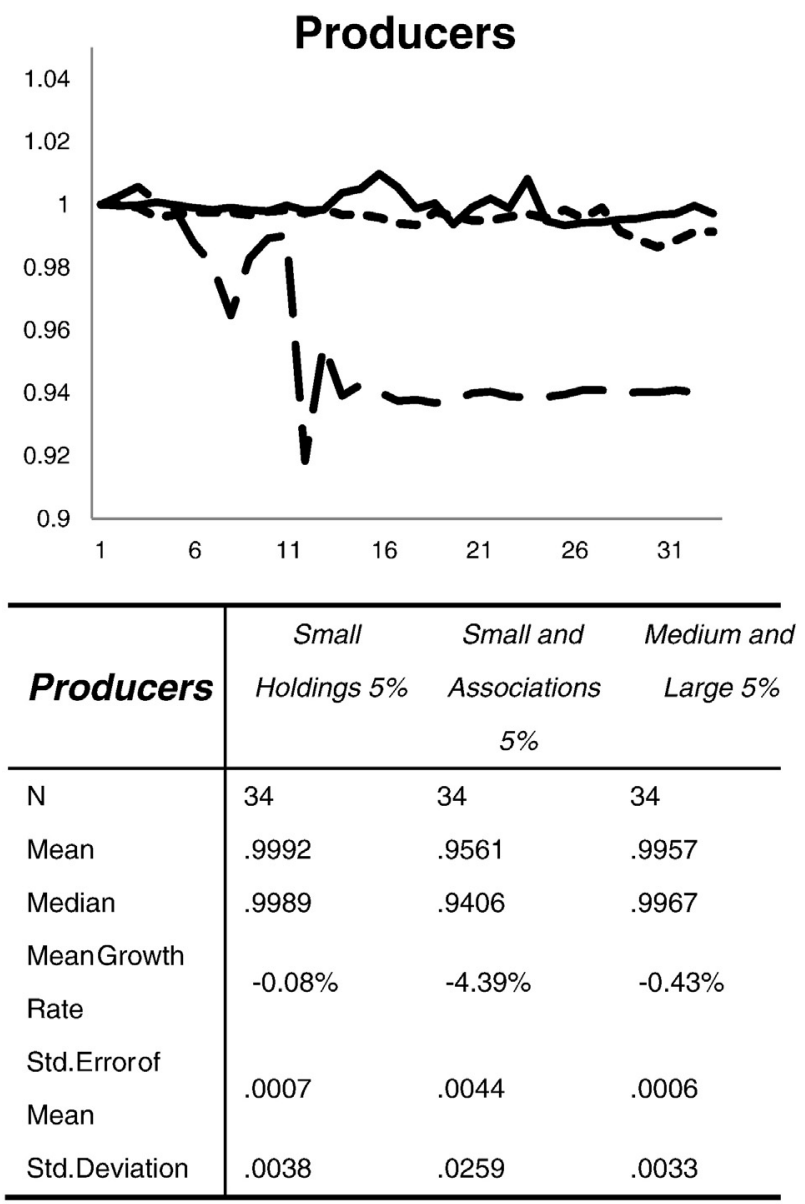

a) Intra-sector dynamics - N. of firms Policy scenario $5 \%$

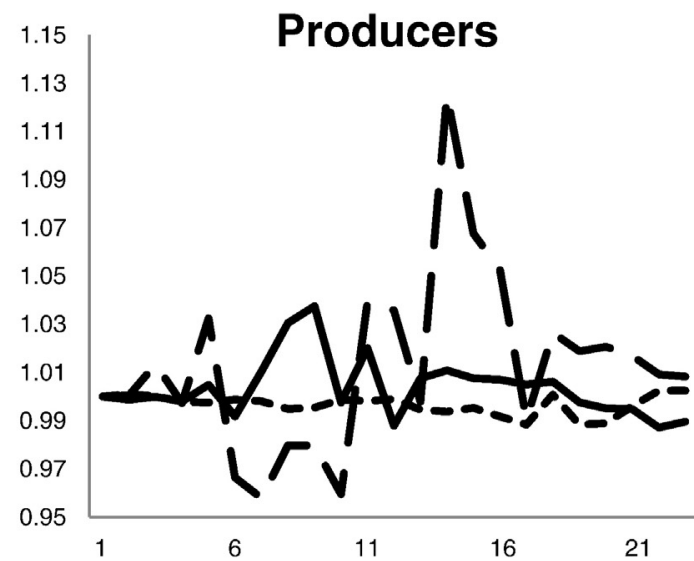

\begin{tabular}{l|lll}
\hline \multirow{2}{*}{ Producers } & \multicolumn{1}{|c}{$\begin{array}{c}\text { Small } \\
\text { Holdings } \\
10 \%\end{array}$} & $\begin{array}{c}\text { Small and } \\
\text { Associations } \\
10 \%\end{array}$ & $\begin{array}{l}\text { Medium / } \\
\text { Large 10\% }\end{array}$ \\
\hline $\mathrm{N}$ & 23 & 23 & 23 \\
Mean & 1.0037 & 1.0129 & 0.9966 \\
Median & 1.0000 & 1.0092 & 0.9979 \\
MeanGrowth & $0.37 \%$ & $1.29 \%$ & $0.34 \%$ \\
Rate & & & \\
Std.Errorof & 0.0026 & 0.0078 & 0.0009 \\
Mean & & & 0.0042 \\
Std.Deviation & 0.0125 & 0.0373 & \\
\hline
\end{tabular}

d) Intra-sector dynamics - N. of firms - Policy scenario $10 \%$

Fig. 6. Intra-sector dynamics - No. of companies, employment and revenue, 5 and 10\% policy scenario. 


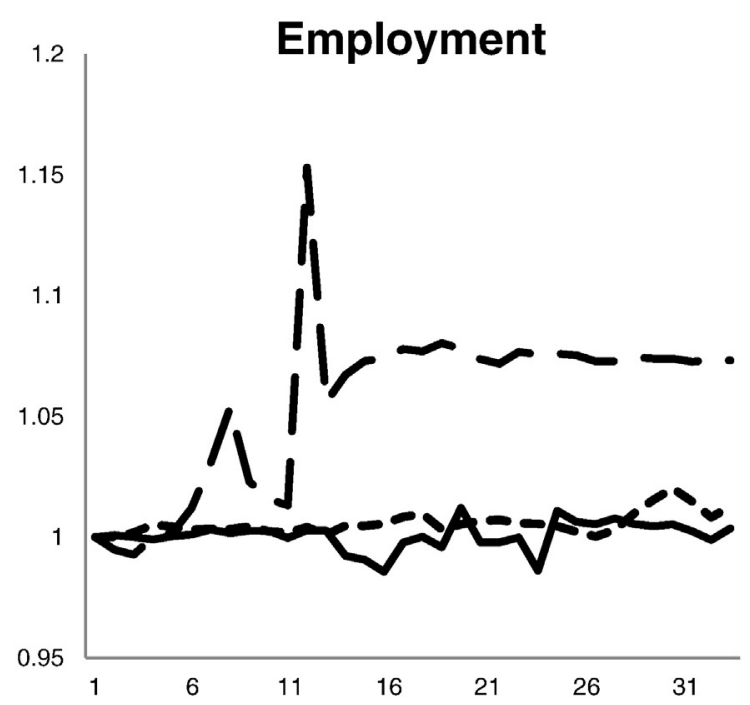

\begin{tabular}{l|lcc}
\hline \multirow{2}{*}{ Employment } & \multicolumn{1}{c}{ Small } & Small and & Medium / \\
& Holdings 5\% & Associations & Large 5\% \\
& \multicolumn{4}{c}{$5 \%$} & \\
\hline $\mathrm{N}$ & 34 & 34 & 34 \\
\hline
\end{tabular}

\begin{tabular}{l|llll}
\hline Mean & 1.0007 & 1.0561 & 1.0057 & \\
Median & 1.0010 & 1.0728 & 1.0046 & \\
MeanGrowth & $0.07 \%$ & $5.61 \%$ & $0.57 \%$ & \\
Rate & & & & \\
Std.Errorof & 0.0010 & 0.0060 & 0.0008 & \\
Mean & & & & \\
Std.Deviation & 0.0058 & 0.0352 & 0.0046 & Std \\
\hline
\end{tabular}

b) Intra-sector dynamics Employment - Policy scenario 5\%

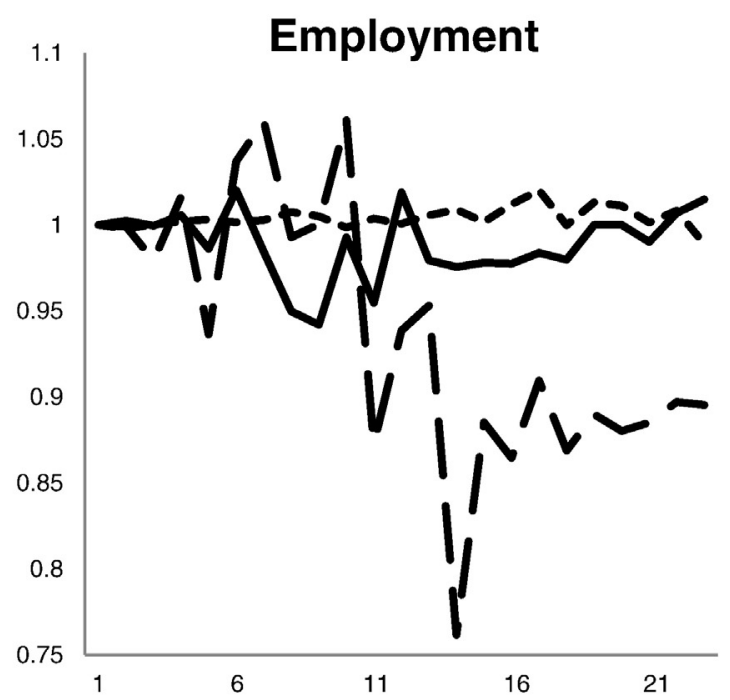

\begin{tabular}{l|lcl}
\hline \multirow{2}{*}{ Employment } & \multicolumn{1}{|c}{ Small } & Small/ & Medium / \\
& Holdings 10\% & $\begin{array}{c}\text { Association } \\
\text { s 10\% }\end{array}$ & Large10\% \\
\hline $\mathrm{N}$ & 23 & 23 & 23 \\
\hline
\end{tabular}

\begin{tabular}{l|lll} 
Mean & .9888 & .9385 & 1.0041 \\
Median & .9902 & .9364 & 1.0028 \\
MeanGrowth & $-1.12 \%$ & $-6.15 \%$ & $0.41 \%$ \\
Rate & & & \\
Std.Errorof & .0043 & .0156 & .0013 \\
Mean & & & .0750 \\
Std.Deviation & .0207 & .0064
\end{tabular}

e) Intra-sector dynamics Employment - Policy scenario 10\%

Fig. 6 (continued).

agent can be characterised by $\{b\}$ and $\{s\}$ when its activities include both buying and selling.

- At a higher degree of aggregation $\{m\}$ defines the four macro categories of Producers; Manufacturing and services to business; Sellers; Consumers.

- Finally the aggregation at system level $\{w\}$, defined as the 'status at time $t$ ' of the whole system resulting from the characteristics of each agent and each category i.e. [R], [M], [Q] and $[\mathrm{N}]$.

The variables (at each level of aggregation) provide the vector of indicators describing the state of the system from which each agent may draw the necessary information to update its behaviour. This process, by capturing informational attitudes, is at the basis of the dynamic adjustment of the Belief-base.
The agent makes its calculation about the states of the variables $\mathrm{M}$ and $\mathrm{R}$. Therefore, $\mathrm{M}$ and $\mathrm{R}$ are the parameters of the 'contracts' negotiated during each step by two connected agents. Contemporarily, $\mathrm{Q}$ and $\mathrm{N}$ are used by each agent as parameters to evaluate the parties' capacity to sustain contractual obligations ( $\mathrm{M}$ and $\mathrm{R}$ ).

The sustainability indicator $=\mathrm{F}(\mathrm{Q}, \mathrm{N})=\mathrm{I}$, is introduced so that each agent can assess and 'feel' the environment by means of a concise index. To this, the process through which the agent forms its Desires and Intentions involves the calculation of two sets of parameters: 1) PRIMARY IMPACT $[P I]$ and 2) TREND [TR].

$P I$ and TR can be seen as the first derivative and the second derivative of the sustainability respectively. Both PI and TR are calculated for all the five levels $\{a, b, s, m, w\}$. 


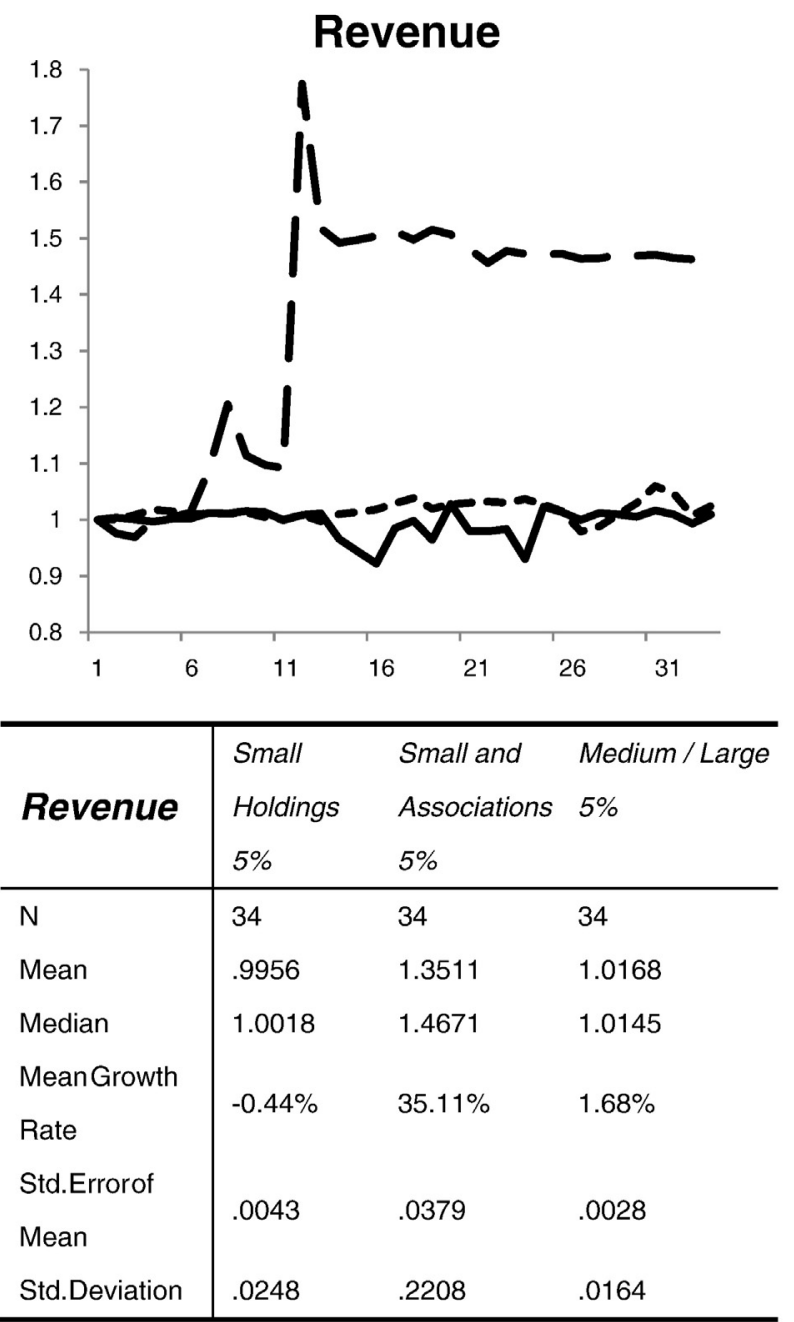

C) Intra-sector dynamics - Revenue Policy scenario $5 \%$

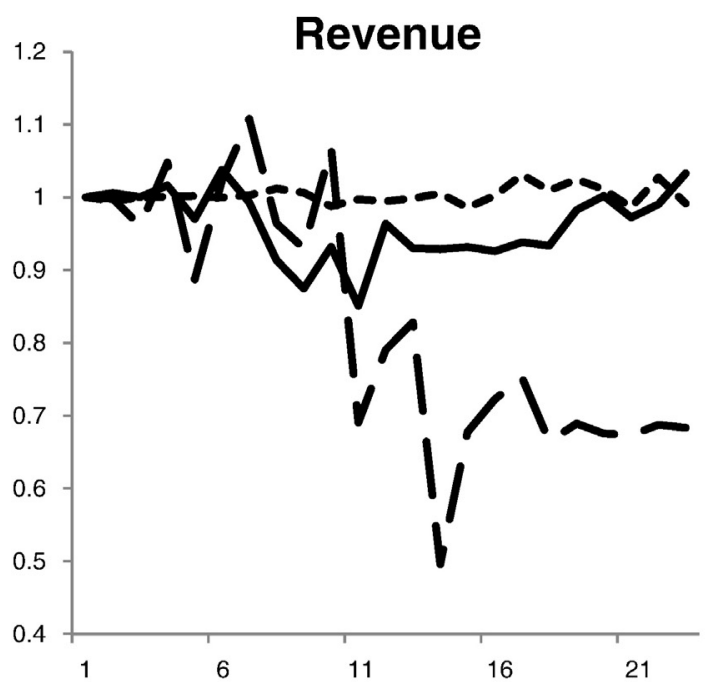

\begin{tabular}{l|lll}
\hline & Small & Small and & Medium/ \\
Revenue & Holdings & Associations & Large 10\% \\
& $10 \%$ & $10 \%$ & \\
\hline $\mathrm{N}$ & 23 & 23 & 23 \\
Mean & .9620 & .8268 & 1.0030 \\
Median & .9700 & .7903 & 1.0008 \\
MeanGrowth & $-3.80 \%$ & $-17.32 \%$ & $0.30 \%$ \\
Rate & & & .0025 \\
Std.Errorof & .0101 & .0354 & .0121 \\
Mean & & & \\
Std.Deviation & .0484 & .1699 & \\
\hline
\end{tabular}

f) Intra-sector dynamics - Revenue - Policy scenario $10 \%$

Fig. 6 (continued)

Each agent evaluates the PI and TR with different relative weights obtained during the fine-tuning process calculated on the basis of statistical and historical data and updated during the previous steps.

The "Priority Equations" employed for each level of analysis are:

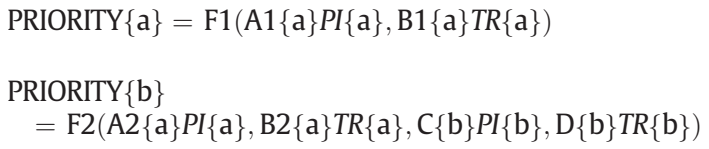

PRIORITY $\{w\}$ $=\mathrm{F} 5(\mathrm{~A} 5\{\mathrm{a}\} P I\{\mathrm{a}\}, \mathrm{B} 5\{\mathrm{a}\} \operatorname{TR}\{\mathrm{a}\}, \mathrm{L}\{\mathrm{w}\} P I\{\mathrm{w}\}, \mathrm{M}\{\mathrm{w}\} \operatorname{TR}\{\mathrm{w}\})$.

Where: A, B, C, D, E, F, G, H, L and M are the parametric coefficients of the equations.

Priority Equations profile the Desires of the agent and capture its motivational attitudes.

Intentions and subsequent deliberative attitudes are obtained through the parametric coefficients A, B, C, D, E, F, $\mathrm{G}, \mathrm{H}, \mathrm{L}$ and $\mathrm{M}$.

Each equation results into a score for the five main issues of interest. These regard the status of the agent itself $\{a\}$, its buyers $\{b\}$, its sellers $\{s\}$, the macro-category of reference $\{m\}$ and the system $\{\mathrm{w}\}$.

The BDI set - Beliefs, Desires and Intentions - drives the behaviour of the agent and it is periodically updated. 
Table 3

Policy impact assessment.

\begin{tabular}{|c|c|c|c|c|c|c|c|c|c|}
\hline \multirow{2}{*}{$\begin{array}{l}\text { Average sectoral } \\
\text { growth }\end{array}$} & \multicolumn{3}{|c|}{ "Light touch" scenario: $5 \%$} & \multicolumn{3}{|c|}{$10 \%$ Implementation scenario } & \multicolumn{3}{|c|}{ "Shock to the system" scenario: $25 \%$} \\
\hline & $\begin{array}{l}\text { No. of } \\
\text { companies }\end{array}$ & Employment & Revenue & $\begin{array}{l}\text { No. of } \\
\text { companies }\end{array}$ & Employment & Revenue & $\begin{array}{l}\text { No. of } \\
\text { companies }\end{array}$ & Employment & Revenue \\
\hline System & Stable & Stable & Increase & $\begin{array}{l}\text { Substantial } \\
\text { decrease }\end{array}$ & $\begin{array}{l}\text { Substantial } \\
\text { increase }\end{array}$ & Stable & $\begin{array}{l}\text { Substantial } \\
\text { decrease }\end{array}$ & $\begin{array}{l}\text { Substantial } \\
\text { increase }\end{array}$ & Increase \\
\hline Primary sector & Decrease & Increase & $\begin{array}{l}\text { Substantial } \\
\text { increase }\end{array}$ & Stable & $\begin{array}{l}\text { Substantial } \\
\text { decrease }\end{array}$ & $\begin{array}{l}\text { Substantial } \\
\text { decrease }\end{array}$ & 1 & 1 & 1 \\
\hline Small holdings & Stable & Stable & Stable & Stable & Decrease & $\begin{array}{l}\text { Substantial } \\
\text { decrease }\end{array}$ & - & - & - \\
\hline $\begin{array}{l}\text { Micro/small and } \\
\text { associations }\end{array}$ & $\begin{array}{l}\text { Substantial } \\
\text { decrease }\end{array}$ & $\begin{array}{l}\text { Substantial } \\
\text { increase }\end{array}$ & $\begin{array}{l}\text { Substantial } \\
\text { increase }\end{array}$ & Increase & $\begin{array}{l}\text { Substantial } \\
\text { decrease }\end{array}$ & $\begin{array}{l}\text { Substantial } \\
\text { decrease }\end{array}$ & - & - & - \\
\hline Medium and large & Stable & Increase & Increase & Stable & Stable & Stable & - & - & - \\
\hline $\begin{array}{l}\text { Manufacturing } \\
\text { and services }\end{array}$ & Increase & Decrease & $\begin{array}{l}\text { Substantial } \\
\text { decrease }\end{array}$ & $\begin{array}{l}\text { Substantial } \\
\text { decrease }\end{array}$ & $\begin{array}{l}\text { Substantial } \\
\text { increase }\end{array}$ & $\begin{array}{l}\text { Substantial } \\
\text { increase }\end{array}$ & 1 & 1 & 1 \\
\hline Retail & Decrease & Increase & $\begin{array}{l}\text { Substantial } \\
\text { increase }\end{array}$ & Decrease & $\begin{array}{l}\text { Substantial } \\
\text { increase }\end{array}$ & Decrease & 1 & 1 & 1 \\
\hline
\end{tabular}

Stable $=$ average growth rates between -0.5 and $0.5 \%$.

Increase/decrease $=$ average growth between \pm 0.5 and $\pm 2.5 \%$.

Substantial increase/decrease $=$ average growth rates over $\pm 2.5 \%$.

At the end of the calculation, the agent is "aware" of the targets to pursue in the following step, thus providing an input for the next stage of "negotiation" according to agents' characteristics, the relative magnitude (and weight) of the coefficients obtained through the priority equations (Desires and Intentions) and on the basis of a hierarchical importance of the achievements for one or more targets.

\section{References}

[1] P.C. Nutt, Examining the link between plan evaluation and implementation, Technol. Forecast. Soc. Change 74 (8) (2007) 1252-1271.

[2] S. Owens, T. Rayner, O. Bina, New agendas for appraisal: reflections on theory, practice, and research, Environ. Plan. A 36 (11) (2004) 1943-1959.

[3] R.T. Ruegg, I. Feller, A Toolkit for Evaluating Public R\&D Investment: Models, Methods, and Findings from the ATP's First Decade, Advanced Technology Programme, National Institute of Standards and Technology, US Commerce Department, 2003.

[4] In: P. Shapira, S. Kuhlmann (Eds.), Learning from Science and Technology Policy Evaluation: Experiences from the United States and Europe, Edward Elgar Publishers, Northampton, MA and Cheltenham, UK, 2003.

[5] A. Gok, J. Edler, The Use of Behavioural Additionality in Innovation Policy-Making, Res. Eval. 21 (4) (2012) 306-318.

[6] J.D. Farmer, D. Foley, The economy needs agent-based modelling, Nature 460 (7256) (2009) 685-686.

[7] S. Cantono, G. Silverberg, A percolation model of eco-innovation diffusion: the relationship between diffusion, learning economies and subsidies, Technol. Forecast. Soc. Change 76 (4) (2009) 487-496.

[8] R. Matthews, N. Gilbert, A. Roach, J. Polhill, N. Gotts, Agent-based land-use models: a review of applications, Landsc. Ecol. 22 (10) (2007) 1447-1459.

[9] N. Schwarz, A. Ernst, Agent-based modeling of the diffusion of environmental innovations - an empirical approach, Technol. Forecast. Soc. Change 76 (4) (2009) 497-511.

[10] J.M. Swaminathan, S.F. Smith, N.M. Sadeh, Modeling supply chain dynamics: a multiagent approach, Decis. Sci. 29 (3) (1998) 607-632.

[11] B. LeBaron, Agent-based computational finance: suggested readings and early research, J. Econ. Dyn. Control 24 (5-7) (2000) 679-702.

[12] W.B. Arthur, L. Tesfatsion, K.L. Judd, Chapter 32 out-of-equilibrium economics and agent-based modeling, Handbook of Computational Economics, vol. 2, Elsevier, 2006, pp. 1551-1564.

[13] L. Tesfatsion, Agent-based computational economics: modeling economies as complex adaptive systems, Inf. Sci. 149 (4) (2003) 262-268.

[14] O. Dilaver Kalkan, M. Bleda, E. Uyarra, Actors, Intentions and Randomness: Evolution of Regional Innovation Networks, SKIN Workshop, Koblenz, Germany, 2011, (31.03-01.04, 2011).
[15] T. Berger, Agent-based spatial models applied to agriculture. A simulation tool for technology diffusion, resource use changes, and policy analysis, Agric. Econ. 25 (2001) 245-260.

[16] G. Deffuant, S. Huet, J.P. Bousset, J. Henriot, G. Amon, G. Weisbuch, Agent-based simulation of organic farming conversion in Allier department, in: M.A. Janssen (Ed.), Complexity and Ecosystem: The Theory and Practice of Multiagent Systems, Edward Elgar Publishing Ltd., Cheltenam, 2002.

[17] K. Happe, K. Kellermann, A. Balmann, Agent-based analysis of agricultural policies: an illustration of the agricultural policy simulator AgriPolis, its adaptation, and behavior, Ecol. Soc. 11 (1) (2006) 49.

[18] L. Pasinetti, Structural Change and Economic Growth, Cambridge Univ. Press, Cambridge, 1981

[19] R.R. Nelson, S.G. Winter, An Evolutionary Theory of Economic Change, Harvard University Press, Cambridge MA, 1982.

[20] The Economy as an Evolving Complex System II, in: W.B. Arthur, S.N. Durlauf, D.A. Lane (Eds.), Proceedings Vol. XXVII, Santa Fe Institute Studies in the Sciences of Complexity, Addison-Wesley, Reading, MA, 1997.

[21] W.B. Arthur, Complexity and the economy, Science 284 (1999) 107-109(2 April 1999):

In: J.S. Metcalfe, J. Foster (Eds.), Evolution and Economic Complexity, Edward Elgar, Cheltenham, UK, 2004.

[22] R.P.F. Holt, J. Barkley Rosser Jr., D. Colander, The complexity era in economics, Rev. Polit. Econ. 23 (3) (2011) 357-369.

[23] R. Ramlogan, J.S. Metcalfe, Restless capitalism: a complexity perspective on modern capitalistic economies, in: E. Garnsey, J. McGlade (Eds.), Complexity and Co-Evolution: Continuity and Change in Socio-economic Systems, Edward Elgar Publishing Ltd., 2006

[24] F. Niglia, D. Gagliardi, C. Battistella, Exploring the impact of innovation policies in economic environments with self-regulating agents in multi-level complex systems, in: M. De Marco, D. Te'eni, V. Albano, S. Za (Eds.), Information Systems: Crossroads for Organization, Management, Accounting and Engineering, Springer Verlag, 2012.

[25] S. Kauffman, The origins of order, Self-Organization and Selection in Evolution, Oxford University Press, New York/Oxford, 1993.

[26] H.A. Simon, The Sciences of the Artificial, Third edition MIT Press, 1998.

[27] M. Wooldridge, N.R. Jennings, Intelligent agents: theory and practice, Knowl. Eng. Rev. 10 (02) (1995) 115-152.

[28] M.W. Macy, R. Willer, FROM FACTORS TO ACTORS: computational sociology and agent-based modeling, Annu. Rev. Sociol. 28 (1) (2002) $143-166$.

[29] M. Wooldridge, Introduction to MultiAgent Systems, John Wiley and Sons Ltd., 2002

[30] M.E. Bratman, Intentions, Plans and Practical Reason, Harvard University Press, Cambridge, MA, 1987.

[31] M.E. Bratman, D.J. Israel, M.E. Pollack, Plans and resource-bounded practical reasoning, Comput. Intell. 4 (3) (1988) 349-355.

[32] M.E. Bratman, Practical reasoning and acceptance in a context, Mind 101 (401) (1992) 1-16 
[33] A.S. Rao, M.P. Georgeff, Modeling rational agents within a BDI-architecture, in: J. Allen, R. Fikes, E. Sandewall (Eds.), Proceedings of the Second International Conference on Principles of Knowledge Representation and Reasoning, KR91, Morgan Kauffman, San Matteo, CA, 1991.

[34] A.S. Rao, M.P. Georgeff, BDI-agents: from theory to practice, Proceedings of the First International Conference on Multiagent Systems (ICMAS'95), 1995.

[35] H.A. Simon, Models of Man, Wiley, New York, 1957.

[36] A. Pokahr, l. Braubach, JADEX User Guide, Distributed System Group, University of Hamburg, Germany, 2007.

[37] ISTAT, Censimento Agricoltura 2010, Available at: http://www.daticensimentoagricoltura.istat.it/2012.

[38] Regione Puglia, Programma di Sviluppo Rurale 2005-2013, Available at: www.regione.puglia.it2006.

[39] G. Marotta, M.A. Perito, Canali distributivi e modelli organizzativi: una prospettiva di sviluppo per i mercati ortofrutticoli all'ingrosso (Distribution channels and organizational models: development prospects for fruit and vegetable wholesale markets), Riv. Econ. Agrar. 55 (3) (2000) 409-438.

[40] G. Fagiolo, A. Moneta, P. Windrum, A critical guide to empirical validation of agent-based models in economics: methodologies, procedures, and open problems, Comput. Econ. 30 (3) (2007) 195-226.

Dimitri Gagliardi is a Research Fellow at the Manchester Institute of Innovation Research (MIoIR) in MBS - The University of Manchester. He holds a PhD in Economics and Institutions awarded by the University of
Bologna (Italy) and completed his Post Doctoral Studies at the Manchester Business School in January 2006. His research experience includes economic analysis and applied research, innovation policy, strategic management of technology and knowledge.

Francesco Niglia is Research Director of KoySLab Ltd. He holds a degree in Engineering from Politecnico of Turin (Italy). His research interests include the development of models for complex systems, the analysis/impact of innovation policies in socio-economic environments, ICT for government solutions and business. Francesco participates in several international workshops for innovation and provides support to the European Commission as expert evaluator and as member of experts' boards.

Dr Cinzia Battistella is a Researcher at the Faculty of Science and Technology, Free University of Bozen-Bolzano. Her scientific interests are in the fields of innovation and strategic management, with primary focuses on corporate foresight and open and collaborative innovation. She published on Technological Forecasting \& Social Change, Management Decision, Production Planning \& Control, Information Research and The Learning Organisation. She participates in various projects on complex systems, foresight and innovation and collaborates with several large companies and research institutions in the areas of foresight and technology roadmapping. 